\title{
Application of the Molecular Adsorber Coating technology on the I onospheric Connection Explorer Program
}

- Nithin S. Abraham

Presented on Wednesday, August 31st, 2016

SPIE Paper 9952-12

Session 3: Space Mission Contamination: Technology Application, Testing and Flight Measurements

Nithin S. Abraham, Mark M. Hasegawa, Mark S. Secunda NASA Goddard Space Flight Center, Greenbelt, Maryland

SPI E Optics + Photonics: Optical Engineering + Applications

Systems Contamination: Prediction, Control, and Performance 2016 (9952)

San Diego Convention Center, San Diego, California, United States of America 


\section{Abstract}

The Molecular Adsorber Coating (MAC) is a zeolite based highly porous coating technology that was developed by NASA Goddard Space Flight Center (GSFC) to capture outgassed contaminants, such as plastics, adhesives, lubricants, silicones, epoxies, potting compounds, and other similar materials. This paper describes the use of the MAC technology to address molecular contamination concerns on NASA's Ionospheric Connection Explorer (ICON) program led by the University of California (UC) Berkeley's Space Sciences Laboratory. The sprayable paint technology was applied onto plates that were installed within the instrument cavity of ICON's Far Ultraviolet Imaging Spectrograph (FUV). However, due to the instrument's particulate sensitivity, the coating surface was vibrationally cleaned through simulated acoustics to reduce the risk of particle fall-out contamination. This paper summarizes the coating application efforts on the FUV adsorber plates, the simulated laboratory acoustic level cleaning test methods, particulation characteristics, and future plans for the MAC technology.

- Keywords: Molecular Adsorber Coating, MAC, zeolite, molecular adsorber, adsorber, adsorption, getter, outgassing, molecular contamination, particulate contamination, sprayable paint technology, coatings, spaceflight applications, I onospheric Connection Explorer, ICON, far ultraviolet instrument, FUV, acoustic cleaning 


\section{Table of Contents}

- Introduction

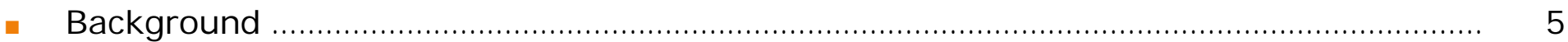

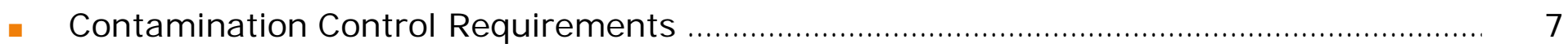

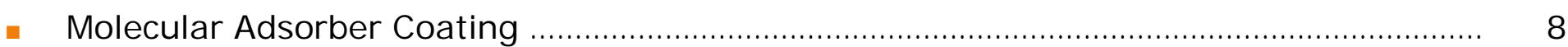

- Flight Application Efforts

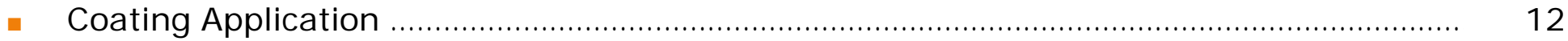

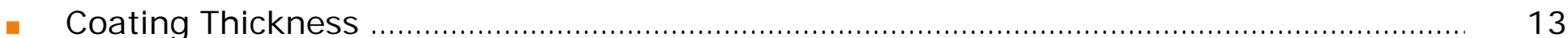

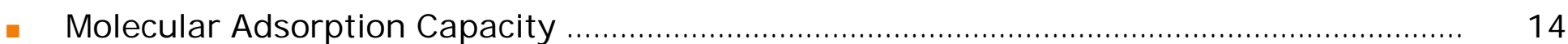

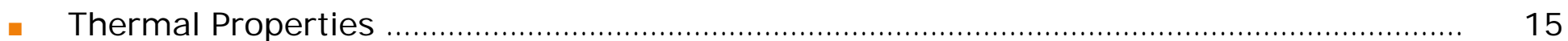

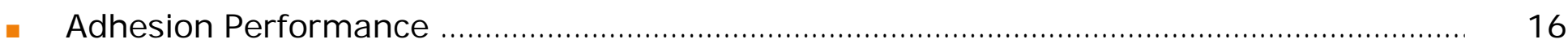

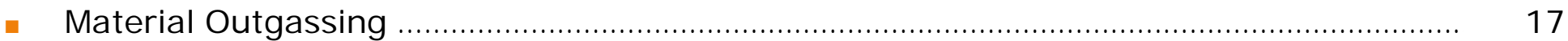

- Simulated Acoustic Cleaning Efforts

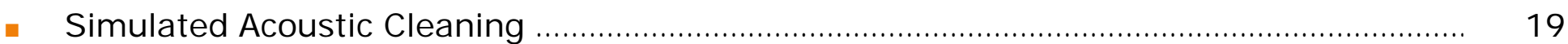

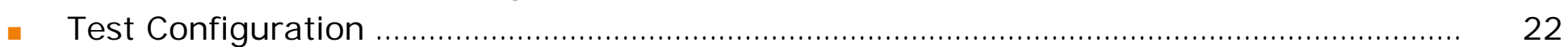

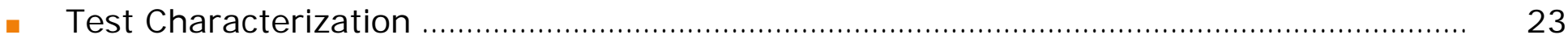

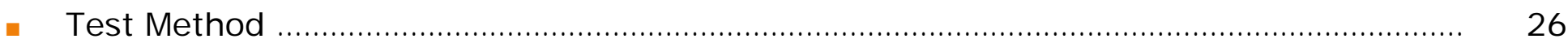

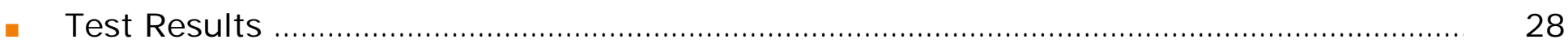

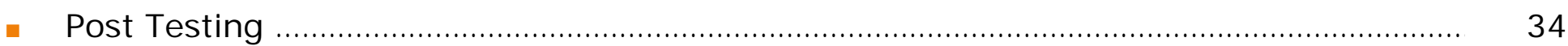

- Conclusions

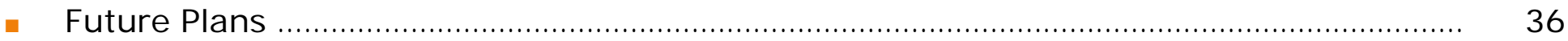

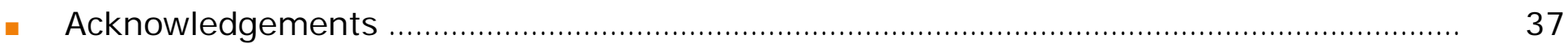

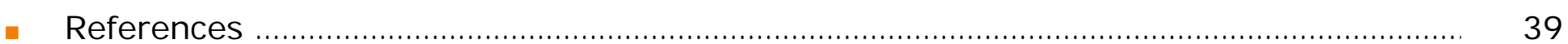

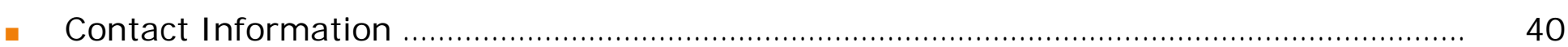




\section{I ntroduction}

- Background

- Contamination Control Requirements

- Molecular Adsorber Coating 


\section{Background}

\section{I onospheric Connection Explorer (I CON)}

- NASA Explorers Program

- Newest addition to its fleet of heliophysics satellites

- Led by University of California (UC) Berkeley's Space Sciences Laboratory

- Launch scheduled for late 2017

- Launch Vehicle: Pegasus XL Rocket

- Comprised of four main instruments

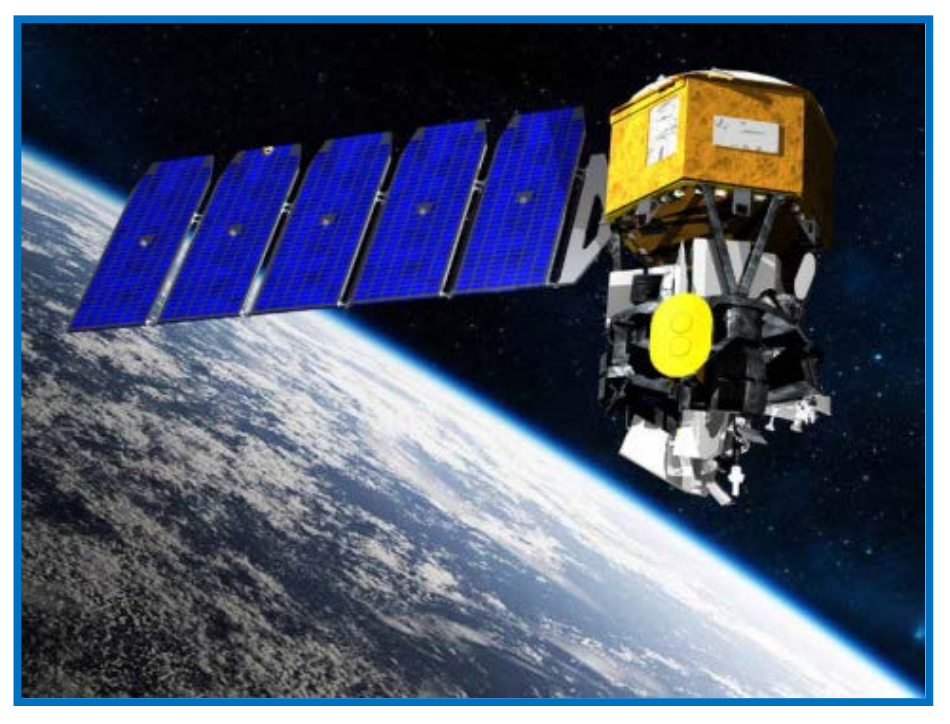

Image Credit: NASA/UC Berkeley

- I VM: I on Velocity Meter

- MI GHTI : Michaelson Interferometer for Global High resolution imaging of the Thermosphere and Ionosphere

- EUV: Extreme Ultraviolet Spectrograph

- FUV: Far Ultra Imaging Spectrograph 


\section{Background}

\section{I onospheric Connection Explorer (ICON)}

- Will investigate changes in the boundary between Earth and the space environment, and study the continuous interactions of space weather and Earth weather, and the sources of ionospheric variations

- These findings will provide a better understanding of the disturbances that are responsible for signal interferences to space based technologies, such as communication and navigation systems

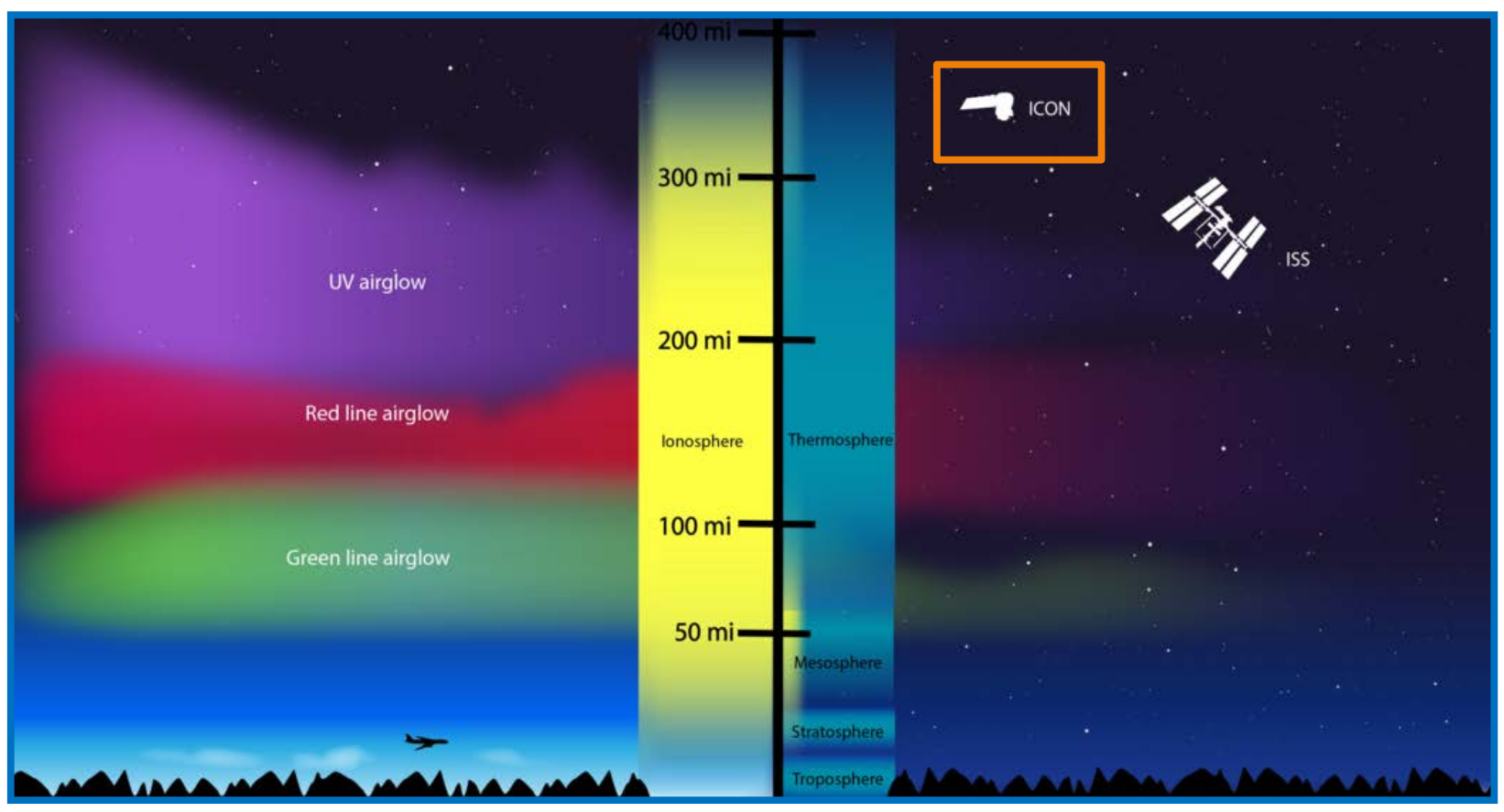

“NASA's ICON mission will orbit above the upper atmosphere,

through the bottom edge of nearEarth space. From this vantage point, ICON will be able to observe both the upper atmosphere made of neutral particles and a layer of charged particles called the ionosphere, which extends from about 50 to 360 miles above the surface of Earth.

Processes in the ionosphere also create bright swaths of color in the sky, known as airglow. ICON will observe how interactions between terrestrial weather and the

ionosphere create such shimmering airglow as well as other changes in the space environment." 


\section{Contamination Requirements}

\section{FUV I nstrument}

- Identified as one of the most sensitive to contamination of the four instruments

- Responsible for measuring the density of ionized gas in the ionosphere and imaging the upper atmosphere in the far ultraviolet range

- Effects of material outgassing within the instrument cavity posed significant challenges to meeting the molecular Cleanliness Levels (CL)

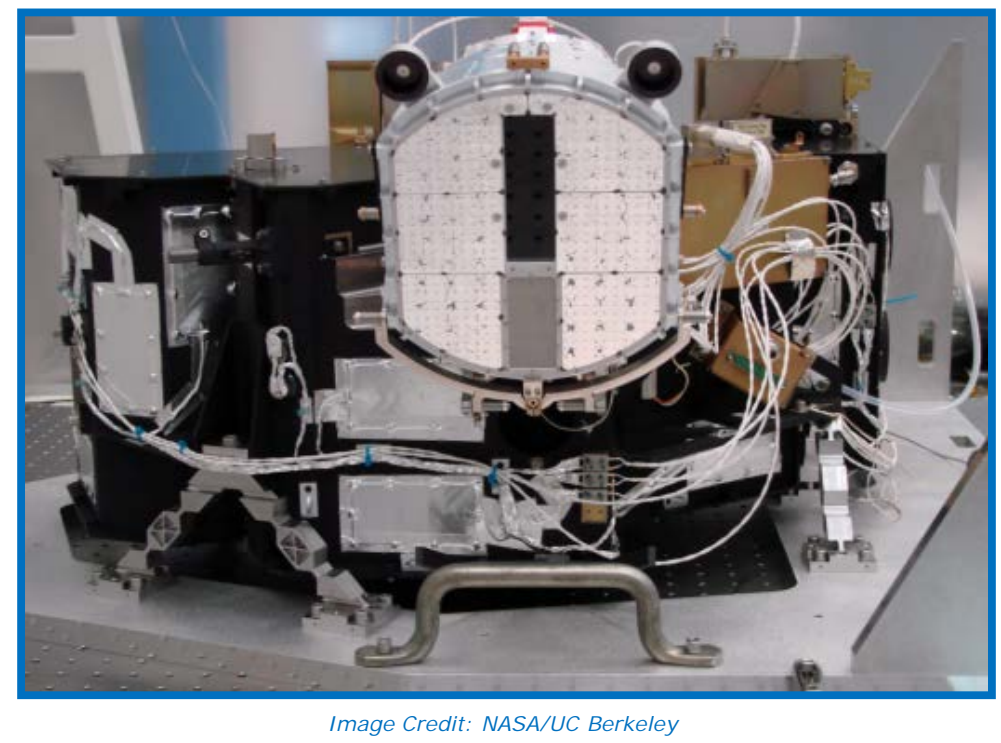

- Outgassing from materials, such as plastics, adhesives, lubricants, silicones, epoxies, potting compounds, and other similar materials, may result in the degradation of the instrument's performance

I CON FUV I nstrument Contamination Cleanliness Level Requirements *

\begin{tabular}{|c|c|c|c|}
\hline Mission Phase & Particulate CL & \multicolumn{3}{|c|}{ Molecular CL } \\
\hline Pre-Integration & 100 & $\mathrm{~A} / 2$ & $0.5 \mu \mathrm{g} / \mathrm{cm}^{2}$ \\
\hline Beginning of Life (BOL) & 500 & A & $1.0 \mu \mathrm{g} / \mathrm{cm}^{2}$ \\
\hline End of Life (EOL) & 500 & $\mathrm{C}$ & $3.0 \mu \mathrm{g} / \mathrm{cm}^{2}$ \\
\hline
\end{tabular}

* The listed particulate and molecular CL are taken from the ICON Contamination Control Plan per IEST-STD-CC1246D 


\section{Molecular Adsorber Coating}

\section{Molecular Adsorber Coating ( MAC)}

- Proposed as a mitigation method to address the FUV instrument's material outgassing concerns

- Developed by NASA Goddard Space Flight Center (GSFC)

- Sprayable, zeolite based and highly porous coating technology that was designed to passively capture outgassed contaminants

- Thereby, reduce the risk of on-orbit molecular contamination from degrading the performance of sensitive interior surfaces on spaceflight hardware and instruments

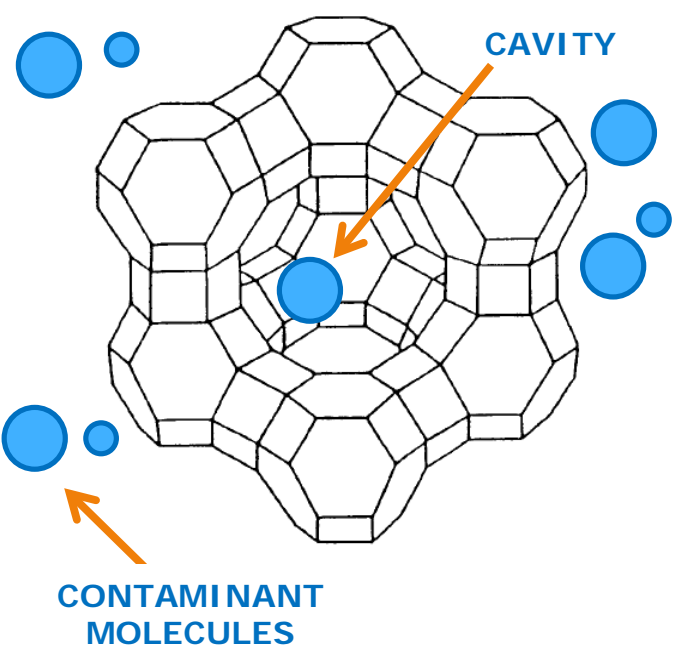

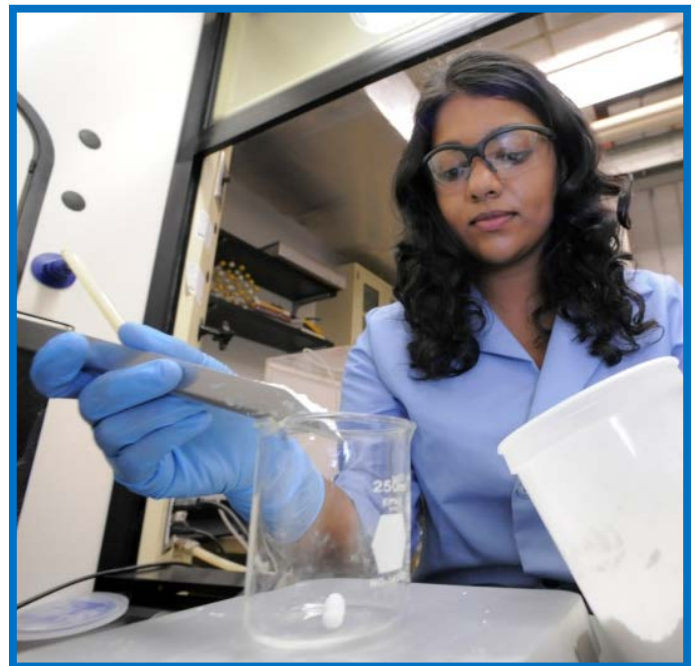

Photo Credit: NASA/Pat Izzo
- Available in both white and black coating variations

- White Molecular Adsorber Coating, GSFC MAC-W

- Black Molecular Adsorber Coating, GSFC MAC-B

- Through GSFC's Internal Research and Development (IRAD) program, significant testing and demonstration efforts were performed in relevant environments (i.e. vacuum) for use on spaceflight applications

- Testing includes: molecular capacitance, thermal/optical property, adhesion performance, thermal cycle, thermal shock, and particle fall-out tests 


\section{Molecular Adsorber Coating NASA}

MAC's Textured Surface Morphology

- Improves molecular adsorption properties of the coating

- High Surface Area

- Surface Roughness

- Highly Porous Structure

- To reduce the likelihood of damage that may occur due to handling, contact with the coating should be limited

- Treat as "no touch" surface

- Rubbing or touching the coating may damage its high surface area, and thus generate particles

- Particle generation may also occur from acoustic or vibration related spacecraft activities, such as:

- Integration and Testing (I\&T) Phase

- Launch Environment
Confocal I maging Microscope ( CI M) Analysis of MAC at 20X Magnification

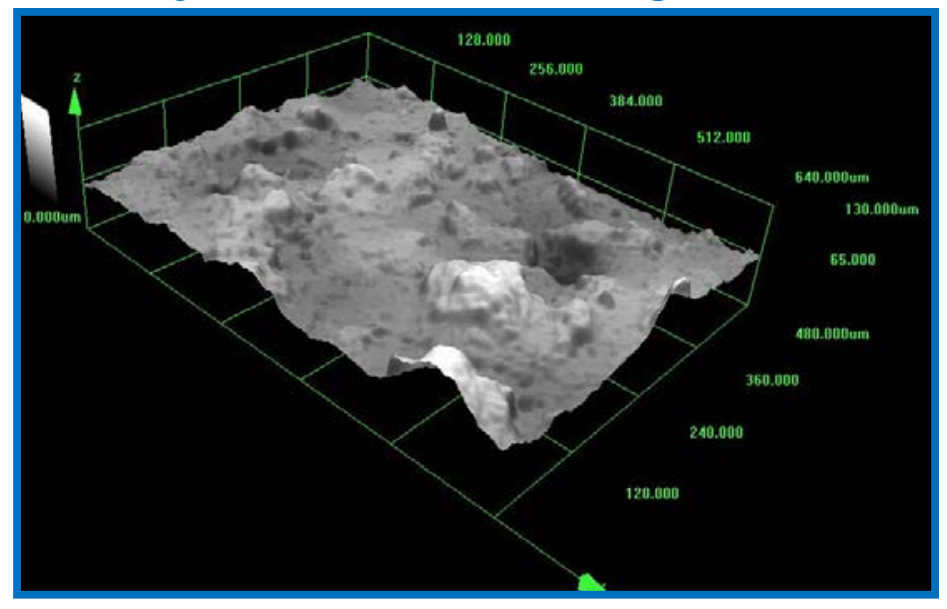

Image Credit: NASA

Scanning Electron Microscope (SEM) Analysis of MAC at 636X Magnification

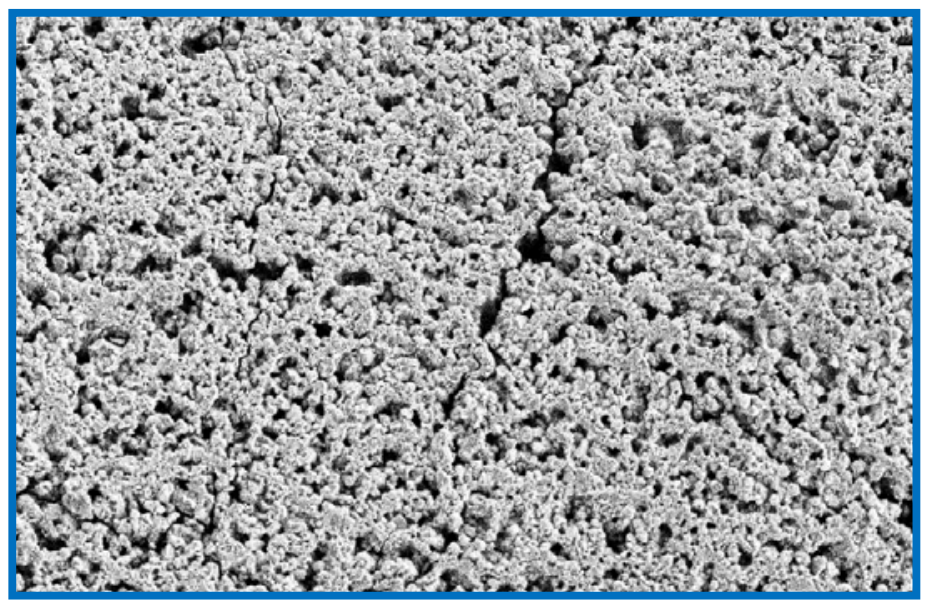




\section{Molecular Adsorber Coating}

\section{ANOTHER CONCERN}

Due to FUV's particulate sensitivity, there is a need to address the potential risk of additional contamination that may occur due to particle fall-out from the coating itself

SOLUTI ON
Implement MAC technology
within instrument to help meet
molecular contamination
requirements
CONCERN
Difficult to meet FUV's highly
sensitive molecular
contamination requirements
due to material outgassing
within instrument

\section{NVESTI GATI ON}

Evaluate MAC's particulation characteristics through various trade studies

\section{SOLUTION}

Mitigate risk by vibrationally cleaning the coating surface through simulated acoustic methods prior to spaceflight to help meet the mission specific particulate cleanliness levels 


\section{Flight Application Efforts}

- Coating Application

- Coating Thickness

- Molecular Adsorption Capacity

- Thermal Properties

- Adhesion Performance

- Molecular Outgassing 


\section{Coating Application}

NASA

- Fabrication: UC Berkeley fabricated six FUV adsorber plates ( 3 in diameter)

\begin{tabular}{|c|c|}
\hline Location & Quantity \\
\hline Spectrograph Bench & 2 \\
\hline Image Bench & 1 \\
\hline Flight Spares & 3 \\
\hline Total & 6 \\
\hline
\end{tabular}

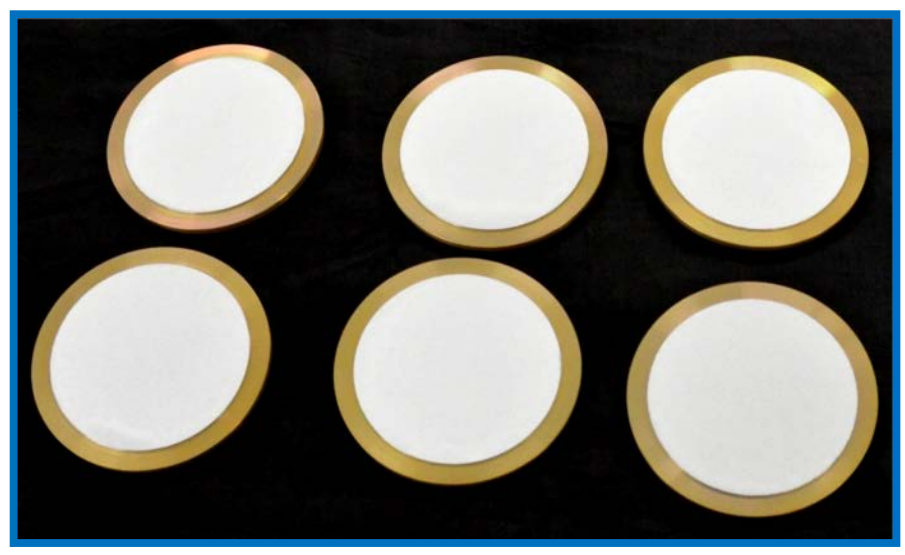

- Design Features:

- Helical coil insert on back side for easy installation within the instrument cavity

- Rigid substrate to limit hardware flexure

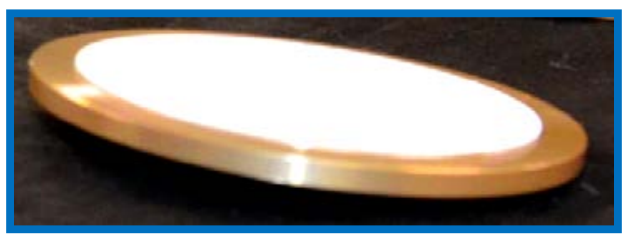

- Application: NASA GSFC applied MAC to adsorber plates on July 2015

- An uncoated 0.25 in border was strategically implemented to reduce coating damage during handling and installation activities

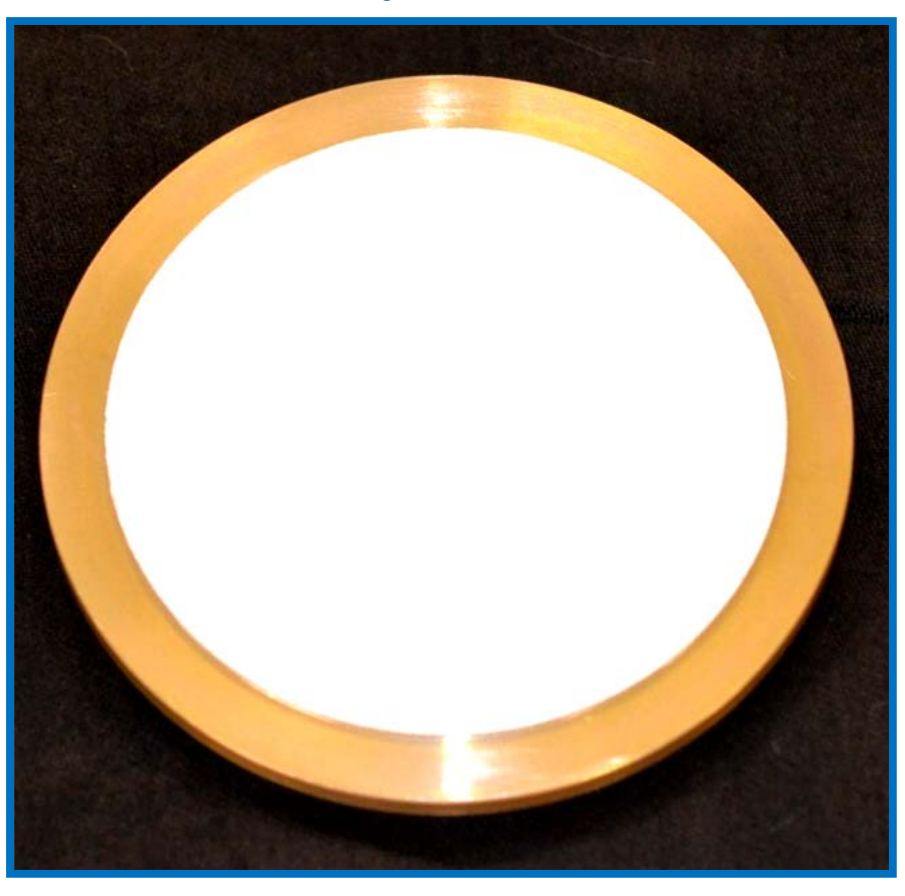




\section{Coating Thickness}

- On average, the coated FUV adsorber plates measured a total coating thickness of 5.5 mils

- Thickness measurement includes both the applied primer and the multiple MAC layers

\section{Summary of Coating Thickness}

\begin{tabular}{|c|c|}
\hline $\begin{array}{c}\text { Flight Hardware } \\
\text { Sample I D }\end{array}$ & $\begin{array}{c}\text { Average Coating } \\
\text { Thickness (mils) }\end{array}$ \\
\hline MAC-FUV-A1 & 6.1 \\
\hline MAC-FUV-A2 & 5.7 \\
\hline MAC-FUV-A3 & 5.5 \\
\hline MAC-FUV-A4 & 4.8 \\
\hline MAC-FUV-A5 & 5.3 \\
\hline MAC-FUV-A6 & 5.5 \\
\hline Total Average Coating Thickness & 5.5 \\
\hline
\end{tabular}

Coating thickness on the flight hardware was evaluated using the Vector TX1 thickness gage manufactured by NDT Instruments. The instrument uses an eddy current to measure the thickness of an applied coating on a metal substrate. Measurements were calibrated with standards of known thicknesses. 


\section{Molecular Adsorption Capacity}

- Also referred to as "molecular capacitance"

- Defined as the measure of the coating's capability to adsorb or entrap outgassed materials (i.e. molecular contaminants)

- Experimental data has shown that the molecular adsorption capacity of the MAC technology is directly proportional to total coating thickness

- The test data used stearyl alcohol at $45{ }^{\circ} \mathrm{C}$ as a model contaminant source at exposures between 88 and 160 hours

Stearyl alcohol is an 18 chain hydrocarbon contaminant that is representative of the commonly outgassed materials found in spaceflight applications

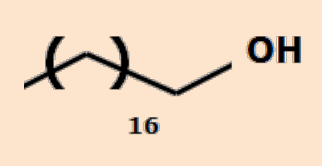

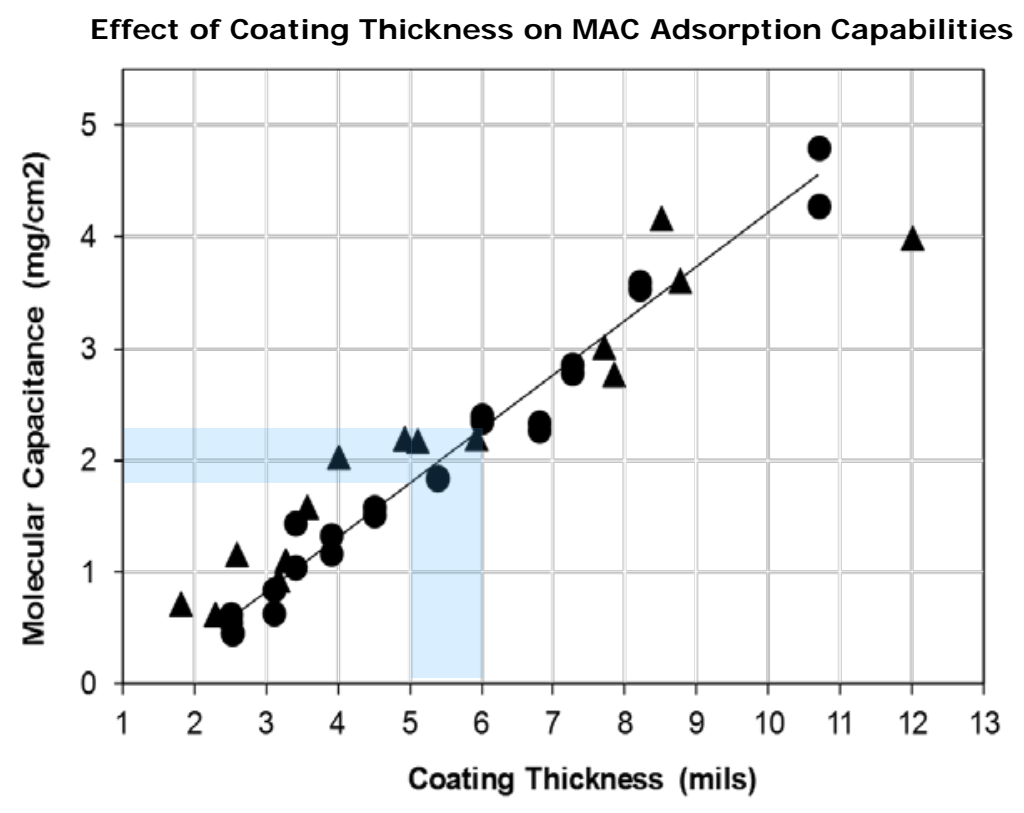

- Based on this set of data, the molecular adsorption capacity for white MAC between 5 to 6 mils thick is approximately $\sim 2 \mathrm{mg} / \mathrm{cm}^{2}$

Estimated Molecular Adsorption Capacity Based on Experimental Data

\begin{tabular}{|c|c|c|c|}
$\begin{array}{c}\text { Coating Diameter } \\
\text { per FUV Adsorber } \\
\text { Plate }\end{array}$ & $\begin{array}{c}\text { Coating Area } \\
\text { per FUV Adsorber } \\
\text { Plate }\end{array}$ & $\begin{array}{c}\text { Molecular } \\
\text { Capacitance } \\
\text { for } 5-6 \text { mils MAC }\end{array}$ & $\begin{array}{c}\text { Estimated } \\
\text { Adsorption } \\
\text { per FUV } \\
\text { Adsorber Plate }\end{array}$ \\
\hline $6.35 \mathrm{~cm}$ & $31.7 \mathrm{~cm}^{2}$ & $\sim 2 \mathrm{mg} / \mathrm{cm}^{2}$ & $\sim 63 \mathrm{mg}$ \\
\hline
\end{tabular}




\section{Thermal Properties}

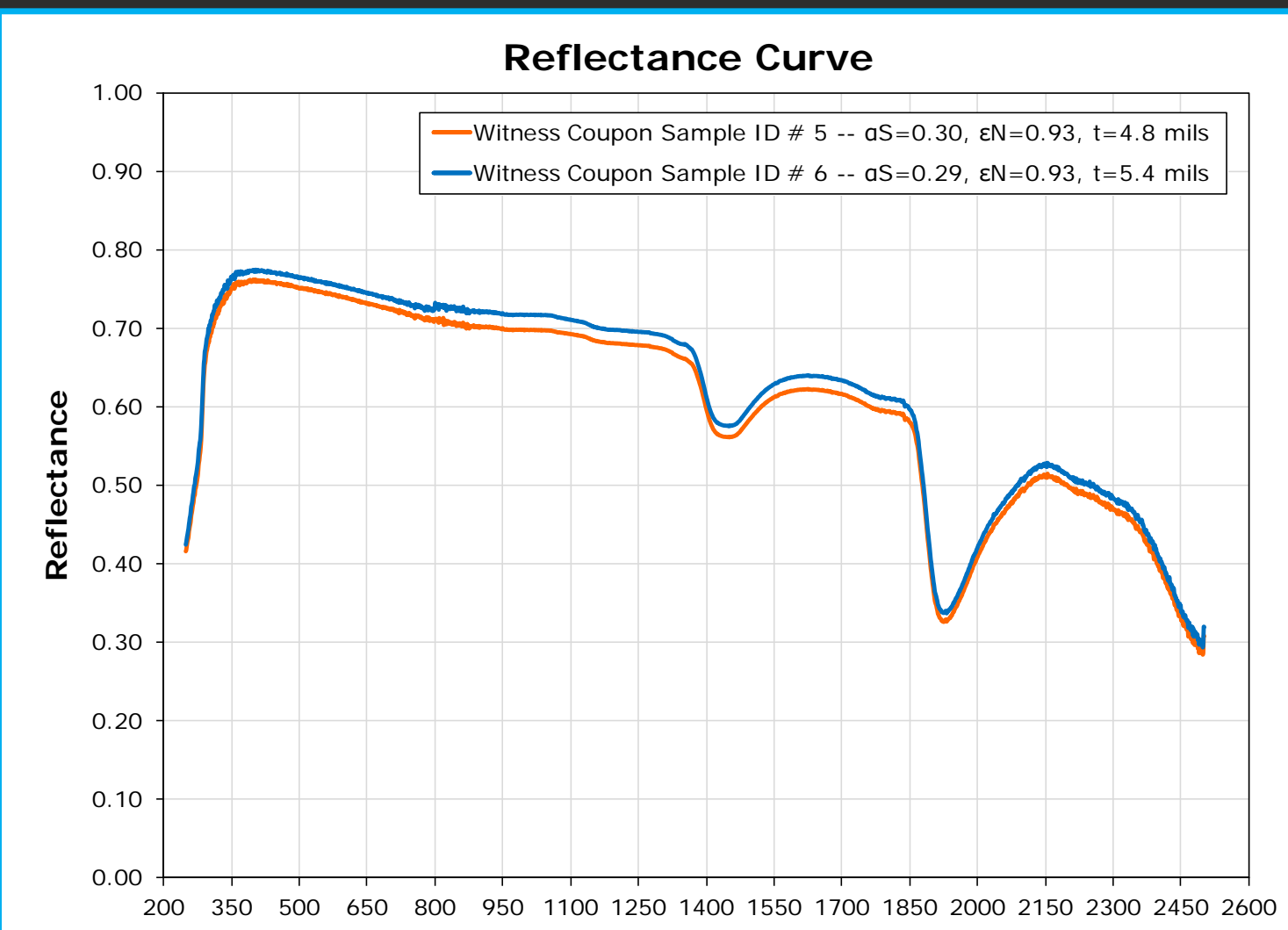

- MAC will not be used for thermal control purposes within the FUV instrument

- However, for reference purposes, thermal property measurements were evaluated on two 2 in by 2 in aluminum witness coupons that were sprayed alongside the FUV flight hardware with white MAC

Solar Absorptance: Calculated using the Varian Cary 5000 spectral reflectometer, which measures the reflectance from 250 to $2500 \mathrm{~nm}$ at an $8^{\circ}$ angle of incidence using the ASTM E903-82 standard test method with a measurement accuracy of \pm 0.02 .

Normal Emittance: Calculated using the Gier-Dünkle DB-100 infrared reflectometer, which measures the normal emittance from 5 to $40 \mu \mathrm{m}$ at room

temperature using the ASTM E408-71 standard test method with a measurement accuracy of \pm 0.02 .

\section{Wavelength $(\mathbf{n m})$}

Summary of Thermal Property Measurements

\begin{tabular}{|c|c|c|c|}
\hline $\begin{array}{c}\text { Witness Coupon } \\
\text { Sample I D }\end{array}$ & $\begin{array}{c}\text { Solar Absorptance } \\
\left(\boldsymbol{a}_{\mathbf{s}}\right)\end{array}$ & $\begin{array}{c}\text { Normal Emittance } \\
\left(\boldsymbol{\varepsilon}_{\mathrm{N}}\right)\end{array}$ & $\begin{array}{c}\text { Total Coating Thickness } \\
(\mathbf{m i l s})\end{array}$ \\
\hline Sample \# 5 & 0.30 & 0.93 & 4.8 \\
\hline Sample \# 6 & 0.29 & 0.93 & 5.4 \\
\hline Average & $\mathbf{0 . 2 9}$ & $\mathbf{0 . 9 3}$ & $\mathbf{5 . 1}$ \\
\hline
\end{tabular}




\section{Adhesion Performance}

- Two 2 in by 2 in witness coupons were used to perform adhesion performance tape tests per Test Method A of ASTM D3359-09

- Test results validate the structural integrity of the coating and the good workmanship process for the coated flight parts

Summary of Adhesion Performance Results

\begin{tabular}{|c|c|c|}
$\begin{array}{c}\text { Witness Coupon } \\
\text { Sample I D }\end{array}$ & $\begin{array}{c}\text { Average Total } \\
\text { Coating Thickness } \\
\text { ( mils) }\end{array}$ & $\begin{array}{c}\text { ASTM D3359-09 } \\
\text { Adhesion Rating }\end{array}$ \\
\hline Sample \# 1 & 5.3 & $4 \mathrm{~A}$ \\
\hline Sample \# 3 & 5.0 & $4 \mathrm{~A}$ \\
\hline & \\
\hline & \\
\hline & \\
\hline
\end{tabular}

Image Credit: NASA 


\section{Material Outgassing}

- ASTM E-595 test method was performed to confirm that the coating meets spaceflight material outgassing criteria in a vacuum environment

Typical Screening Criteria for Spaceflight Materials

- Collected Volatile Condensable Material (CVCM) $\leq 0.10 \%$

- Total Mass Loss (TML) $\leq 1.0 \%$

Material Outgassing Properties of White MAC

\begin{tabular}{|c|c|c|}
\hline TML & WVR at 50\% RH & CVCM \\
\hline $11.19 \%$ & $11.03 \%$ & $0.01 \%$ \\
\hline
\end{tabular}

- MAC exhibits the following properties due its chemical composition which is comprised of inorganic materials, such as zeolite

- Low outgassing properties in vacuum conditions

- CVCM is $0.01 \%$

- Hygroscopic properties at ambient conditions

- Water Vapor Release (WVR) at $50 \%$ Relative Humidity (RH) is $11.03 \%$

The relatively high TML is a result of water moisture loss in a vacuum environment, and not due to material outgassing! 


\section{Simulated Acoustic Cleaning Efforts}

- Simulated Acoustic Cleaning

- Test Configuration

- Test Characterization

- Test Method

- Test Results

- Post Testing 


\section{Simulated Acoustic Cleaning}

\section{Launch Environment}

- During launch, a spacecraft is exposed to extreme acoustic conditions that produce high levels of vibrations

- Consequently, it is important for the payload structure and its components to endure such an intense environment

\section{Acoustic Test Chamber}

- At NASA GSFC, these acoustic induced vibrations are simulated in a 42 foot tall acoustic test chamber for ground testing purposes

- Houses 6 foot wide horns that generate acoustic noise as high as 150 decibels

- Sound produced by alternating flow of gaseous nitrogen

- Payload exposed to this "simulated" acoustic environment for typically two minutes during testing

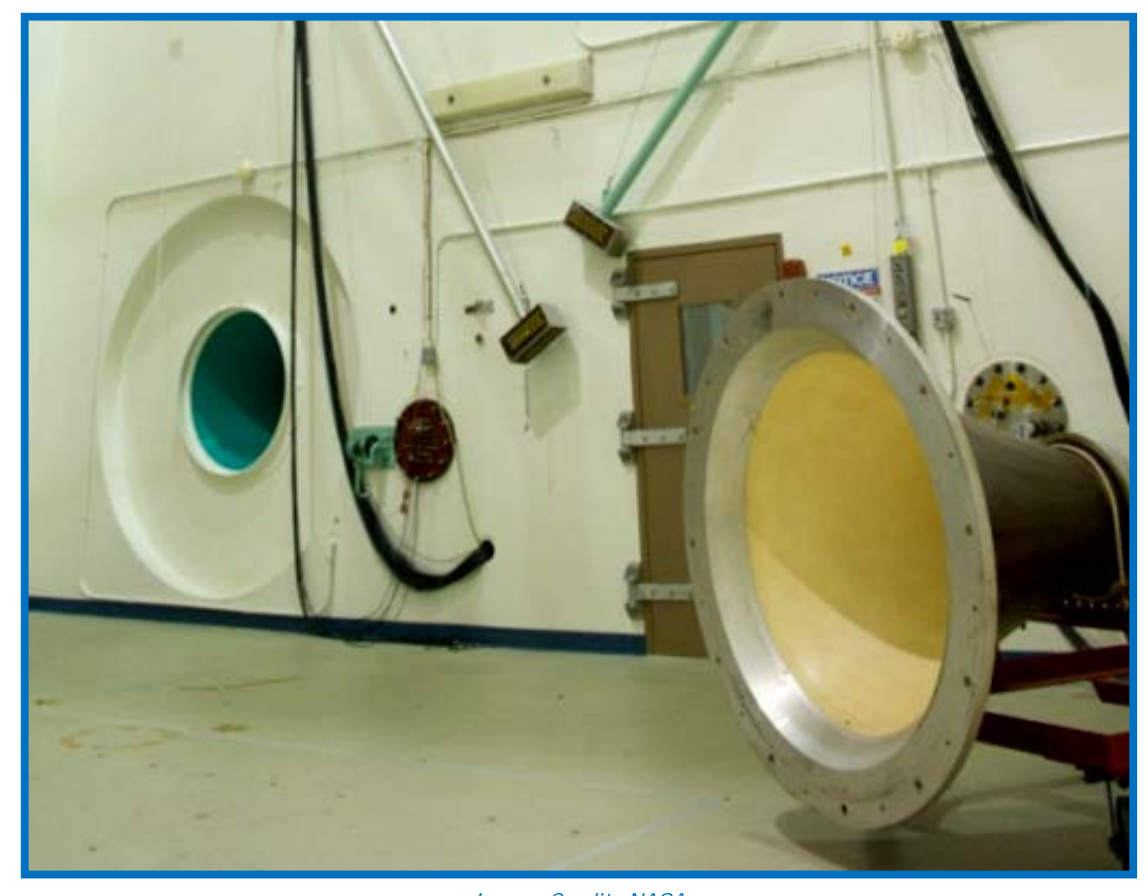




\section{Simulated Acoustic Cleaning}

\section{Simulated Acoustic Cleaning Test}

- Designed a simulated laboratory level acoustic cleaning test

- To mitigate risk of particle fall-out from coating due acoustic level vibrations related to spacecraft activities and launch environments

- Similar concept to NASA's acoustic test chamber used for ground testing

- In industry, acoustic cleaning is a common maintenance practice that involves dislodging solid particles through sound transmission
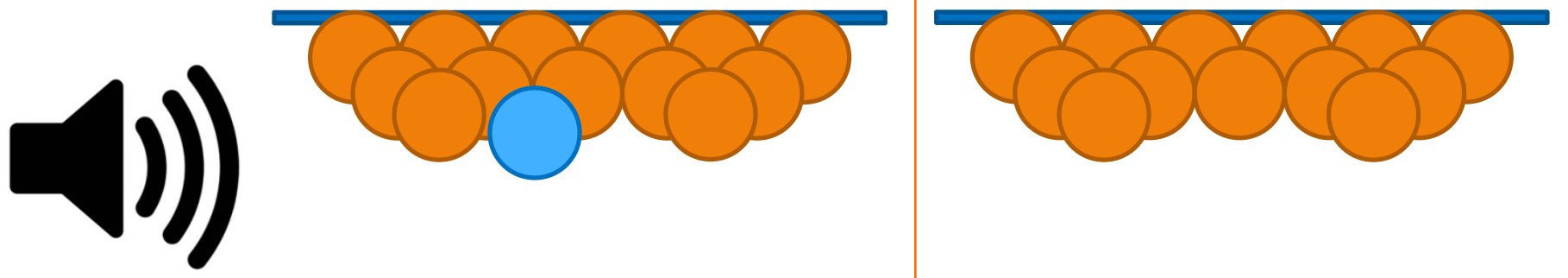

- Similarly, this acoustic cleaning method will be used to vilbrationally shake or remove particles loose from the coating's textured surface that may at a later time come off due to vibroacoustic impacts of a launch environment 


\section{Simulated Acoustic Cleaning}

\section{Trade Study}

- In 2014, NASA GSFC conducted simulated acoustic cleaning trade studies on flat aluminum substrates coated with MAC

- Purpose:

- To evaluate particulation characteristics of MAC due to acoustic induced vibrations

- Results:

- Demonstrated correlation between coating thickness and particulate shedding effects

- Showed significant reduction of particle fall out when coating is acoustically cleaned or experiences a simulated "shake"

- This simulated acoustic cleaning technique will be

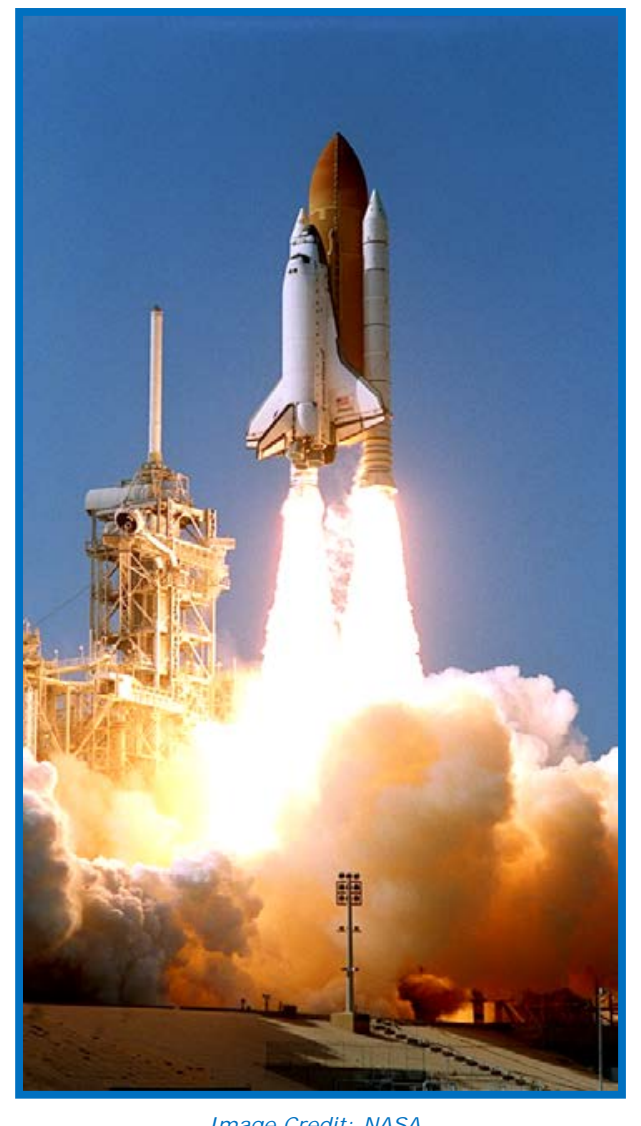

Image Credit: NASA performed on ICON's flight hardware prior to spaceflight use to help meet the mission's particulate cleanliness levels, and considerably reduce the threat of excess particulate contamination within the FUV instrument 


\section{Test Configuration}

\section{Acoustic Cleaning Test Configuration}

- Laboratory bench scale simulation of vibration forces that are applied in the NASA GSFC acoustic test chamber

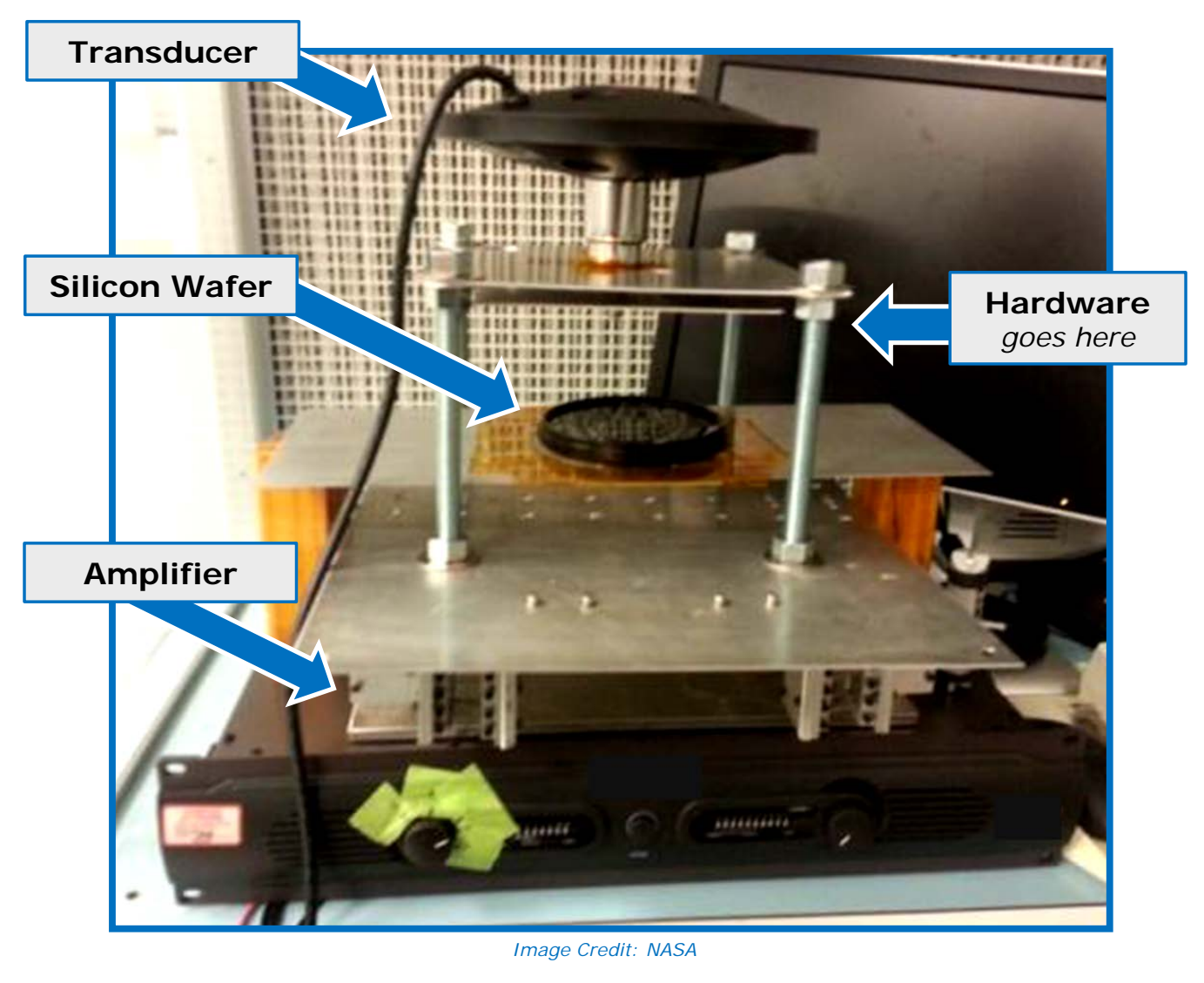

\section{COMPONENT FLOW DIAGRAM}

1. Brown Noise Audio File

- From connected computer

- Provides input signal

\section{Audio Power Amplifier}

- Increases power of audio to produce speaker level noise

- Provides output signal

\section{Tactile Sound Transducer}

- Transfers energy of output signal

- Capable of transmitting low frequency vibrations onto surfaces - Mechanically transfers acoustic energy to mounted hardware

\section{Coated Flight Hardware}

- Experiences the transferred acoustic energy's vibrations and shaking

\section{Silicon Wafer}

- Collects loose particles removed due to these vibrations/shaking - Placed below hardware (where coating is facing wafer) 


\section{Test Characterization}

\section{Amplifier Settings}

- Determine appropriate amp setting that produces levels similar to flight conditions

- Expected overall random vibration response level for the FUV instrument is $\sim \mathbf{1 4} \mathbf{G}_{\mathrm{rms}}$

- Uncoated non-flight FUV adsorber plates

- Mounted to the test apparatus using a custom designed adaptor fitting attachment, which screws into the helical coil insert on the backside of the hardware

- Two accelerometers were attached to the hardware on two opposite sides

- Subjected to various amp settings to evaluate acoustic induced vibration response via accelerometer signals

- Signal analyzer was used to record responses of acoustic cleaning activity on the hardware at various amp settings
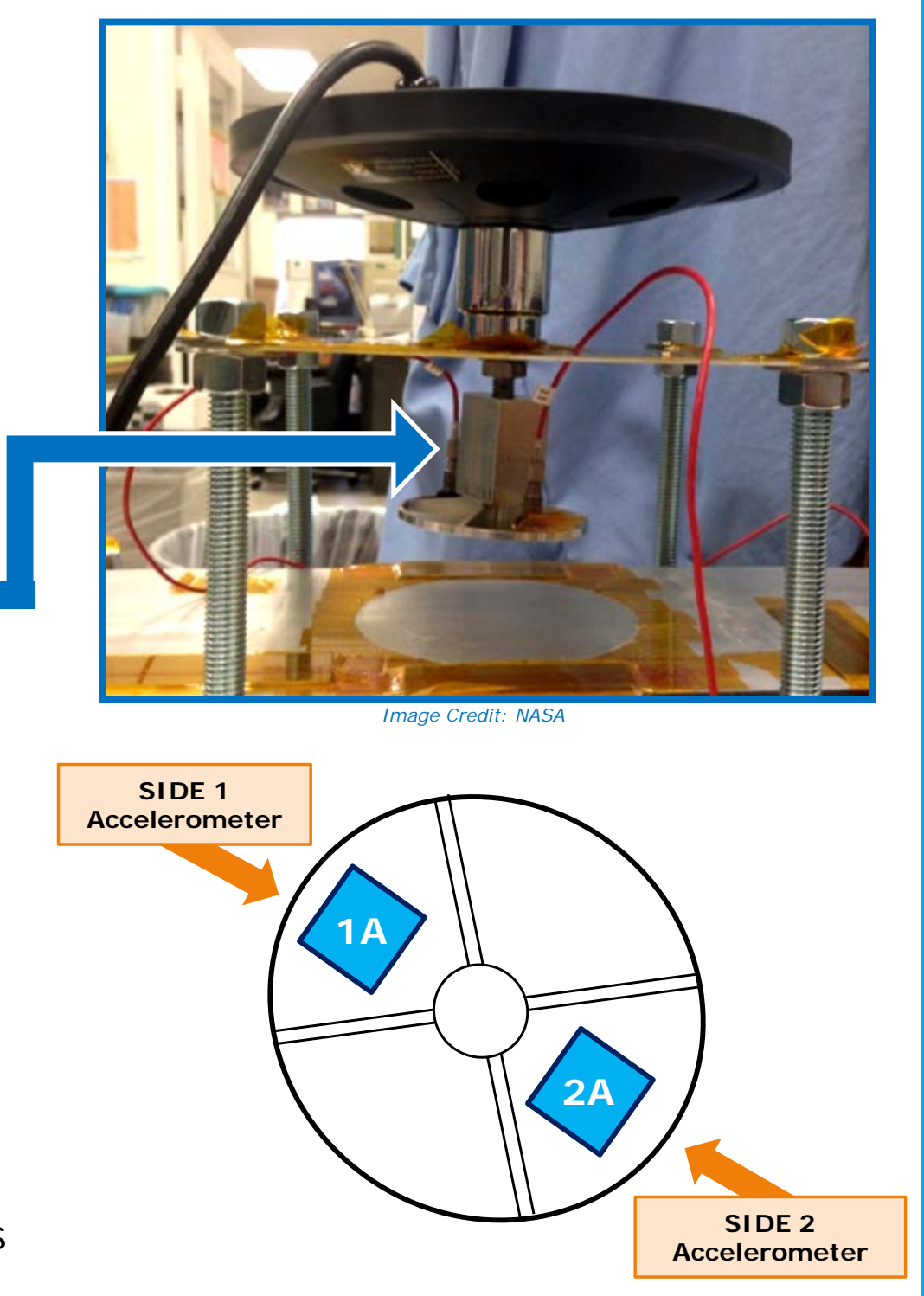


\section{Test Characterization}

\section{Accelerometer Response at Various Amp Settings}

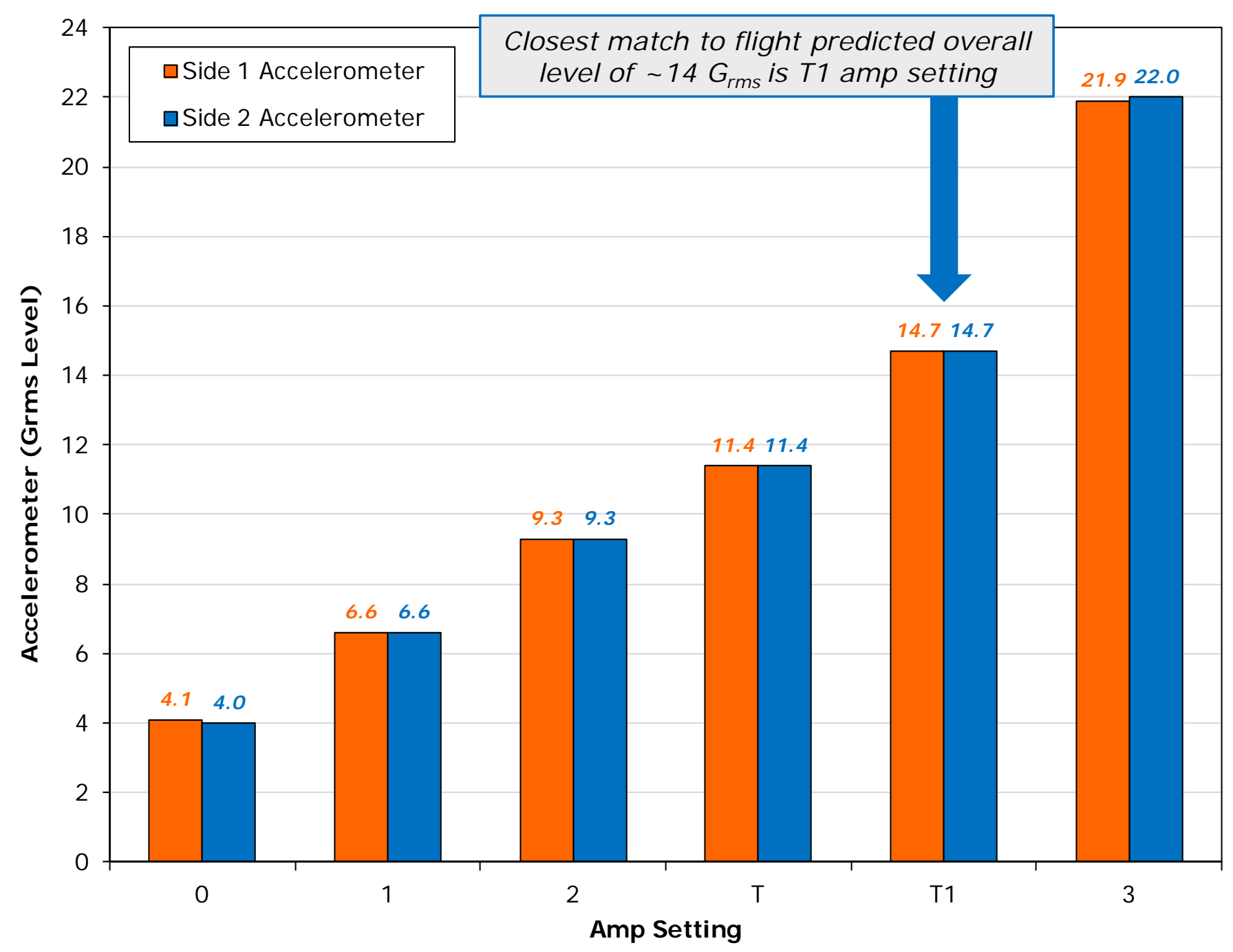

Both accelerometers showed the same $\mathrm{G}_{\mathrm{rms}}$ response for each different setting.

This indicates that the mounted hardware is subjected to even distribution of the acoustic induced vibrations. 


\section{Test Characterization}

\section{Power Spectral Density and Frequency Response}

of both accelerometers at "T1" amp setting

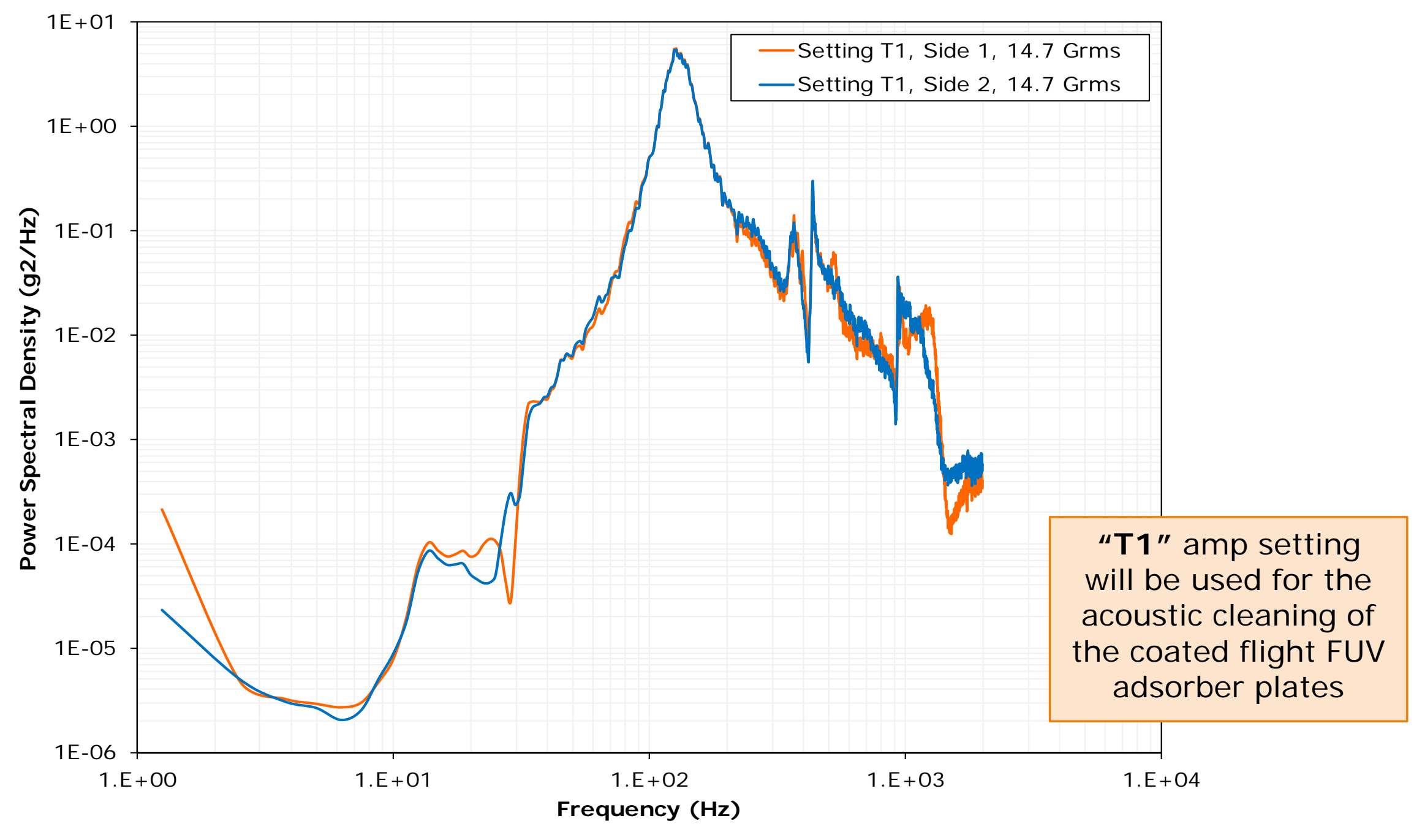




\section{Test Method}

- Silicon wafers are scanned using an automated II mage Analysis ( I A) system comprised of a microscope and analyzer software

- IA scan provides particle count data, which is used to determine:

- Percent Area Coverage (PAC)

- Based on total area covered by particles over total area scanned by IA microscope

- Cleanliness Level (CL)

- Based on surface particle obscuration

Based on empirical relations from the paper "Surface particle obscuration and BRDF predictions" by Ma, Fong, and Lee. CL empirical relations represent spherical shaped particles and cylindrical-hemispherical shaped particles.

- Coated flight hardware is securely mounted on test apparatus underneath transducer

- Coated side of hardware is facing down towards where the silicon wafer will be placed on the test apparatus

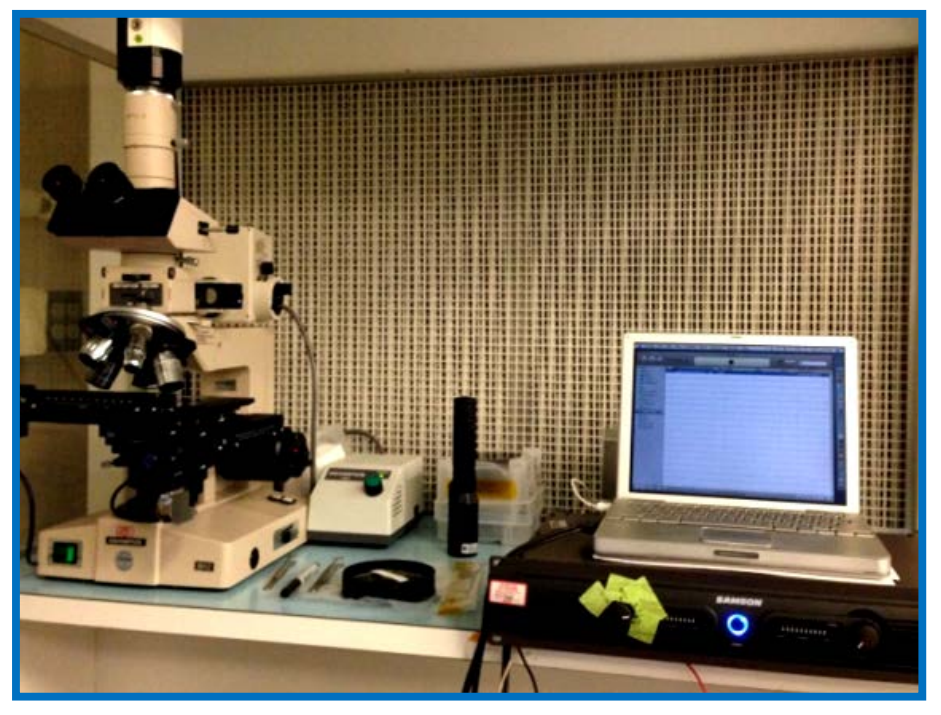

Image Credit: NASA

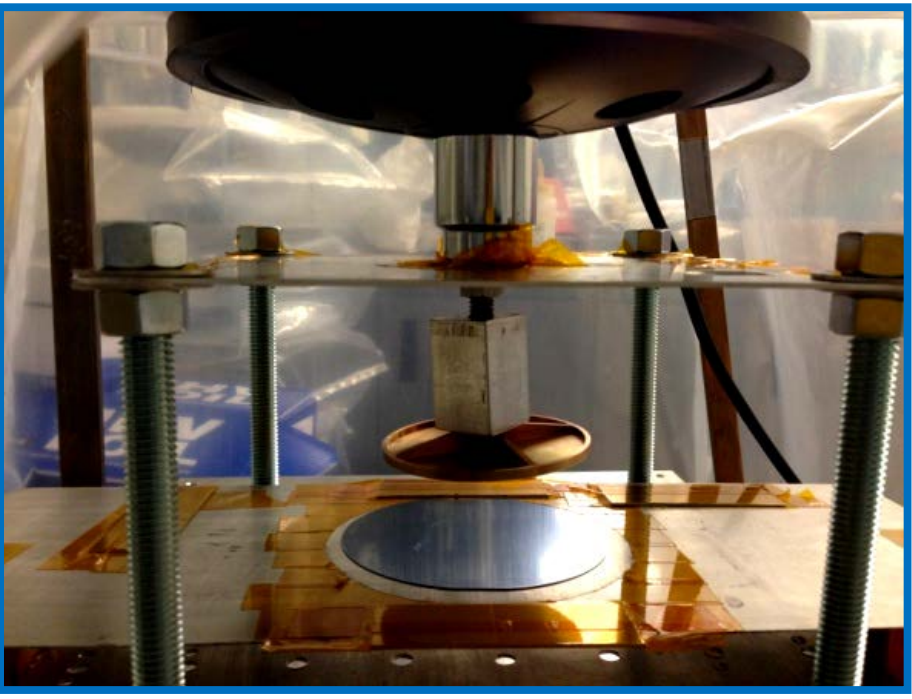




\section{Test Method}

- Summary of test method used to perform a simulated acoustic cleaning:

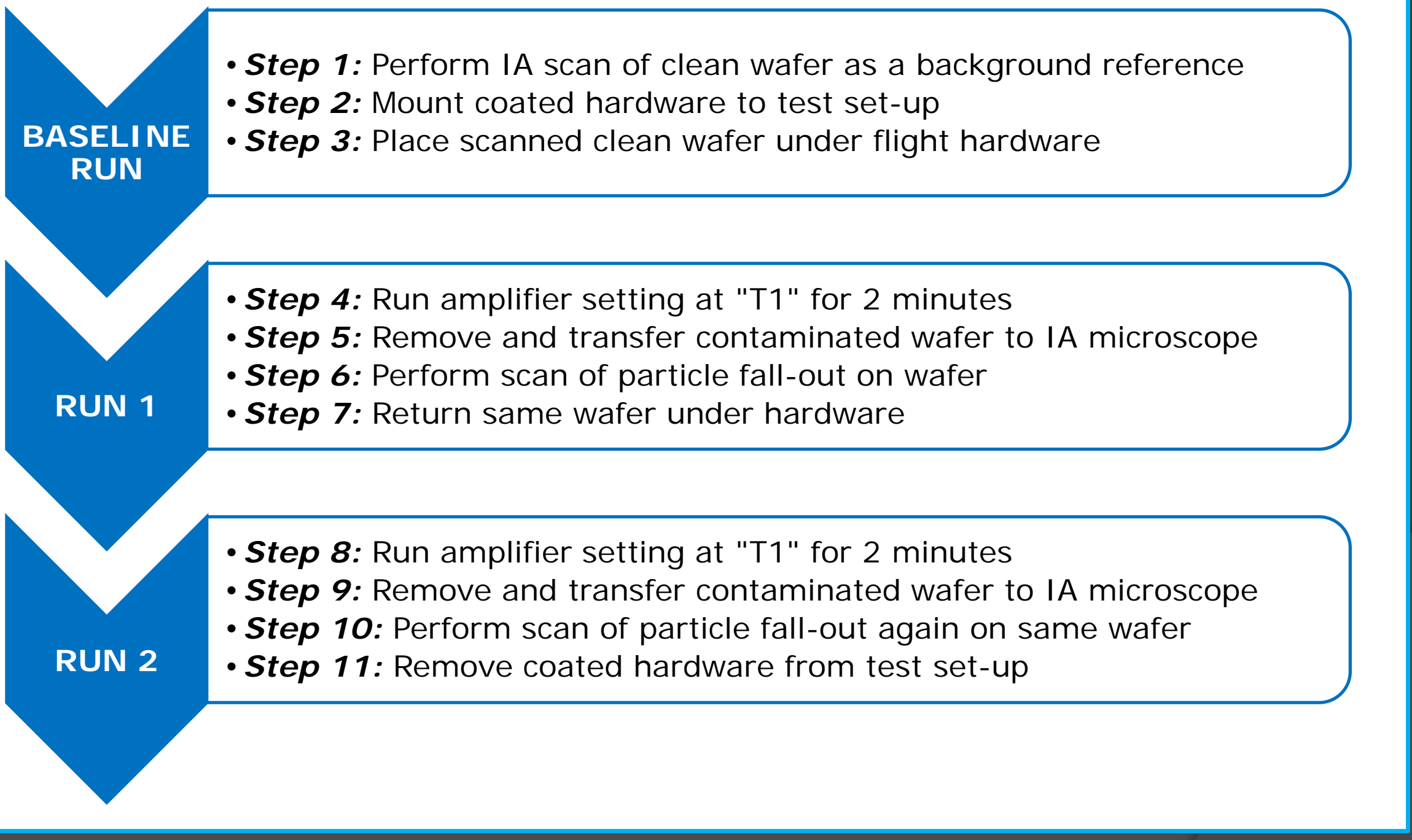




\section{Test Results}

- Performed a total of six simulated acoustic cleaning tests

- One wafer was used for three runs per coated FUV adsorber plate

- Three runs include:

BASELI NE RUN

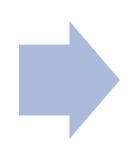

RUN 1

RUN 2

- Coated flight hardware were designated as A1 through A6

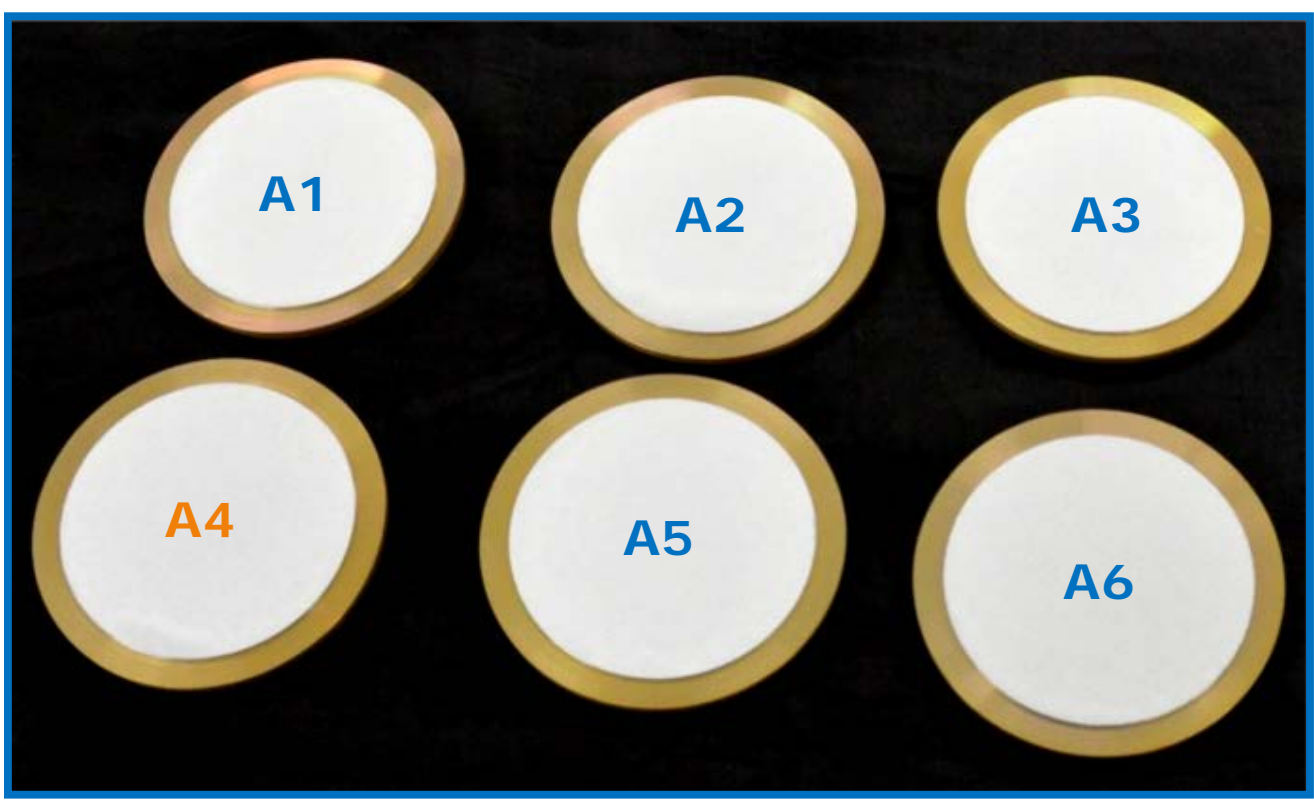

- Test efforts for A4 experienced particulate contamination from the supplied wafer case

- This error resulted in an inconclusive analysis of data

- As a result, fall-out data for A4 was removed from the findings presented here 


\section{Test Results}

\section{Percent Area Coverage (PAC)}

- Based on total area covered by particles over total area scanned by IA microscope

$$
\text { PAC }=\frac{\text { Particle Obscured Area }}{\text { Wafer Scan Area }} * 100
$$

\section{RUN 1}

\section{One Acoustic "Shake"}

- Reflects the amount of loose MAC particles that were removed during the initial excitation experienced from the first simulated acoustic vibrations

- Initial PAC varies per sample due to the variable surface texture of the applied coating

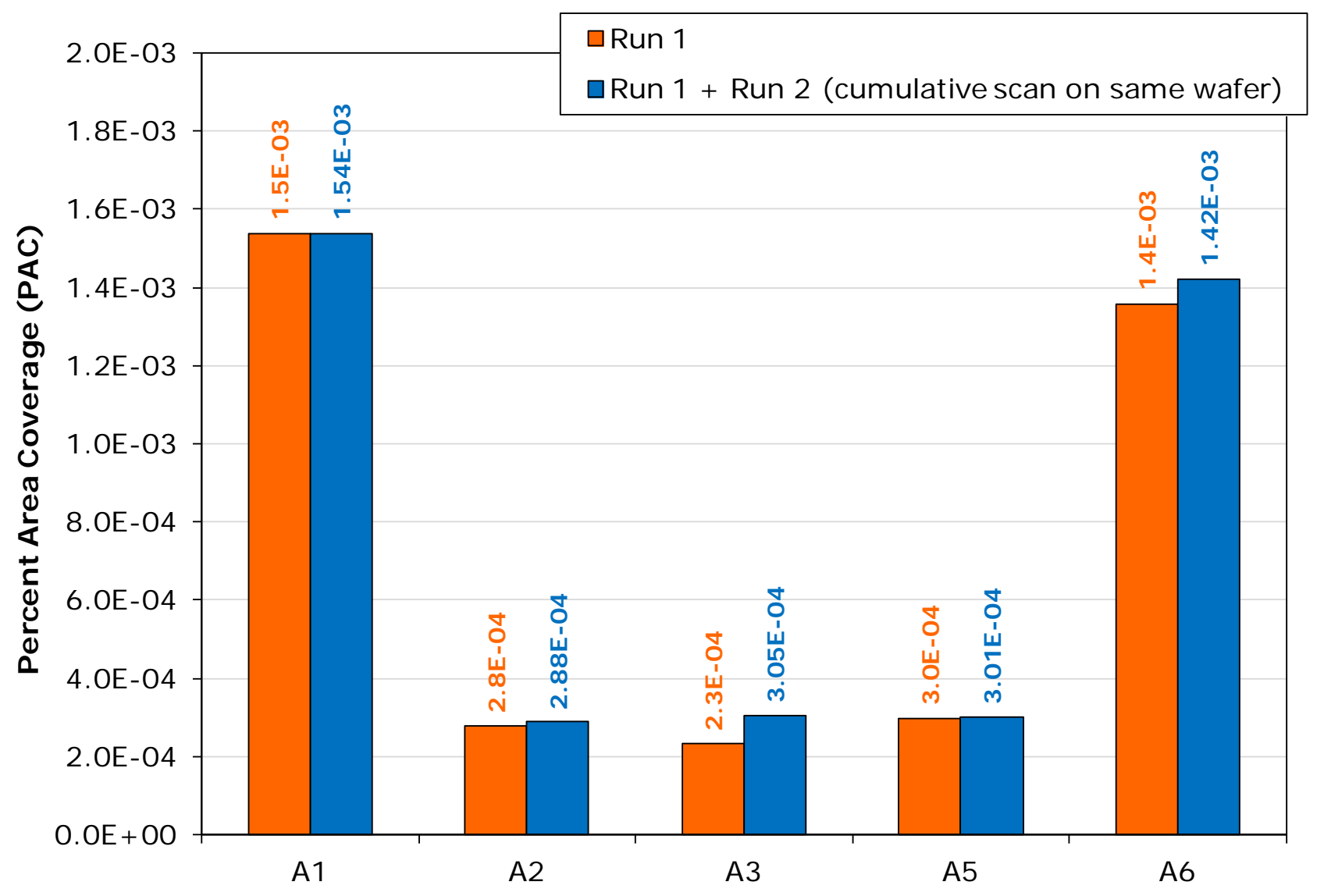

Flight Hardware Sample I D MAC-FUV-A\# 


\section{Test Results}

Percent Area Coverage (PAC)

- Based on total area covered by particles over total area scanned by I A microscope

$$
\text { PAC }=\frac{\text { Particle Obscured Area }}{\text { Wafer Scan Area }} * 100
$$

\section{RUN 1 + RUN 2}

\section{Two Acoustic "Shakes"}

- Reflects the cumulative PAC from the two simulated acoustic vibrations

- Cumulative PAC remained about the same as Run 1 PAC

- Suggests that no additional particles (or very little in some cases) were additional removed from the coating surface during the second run

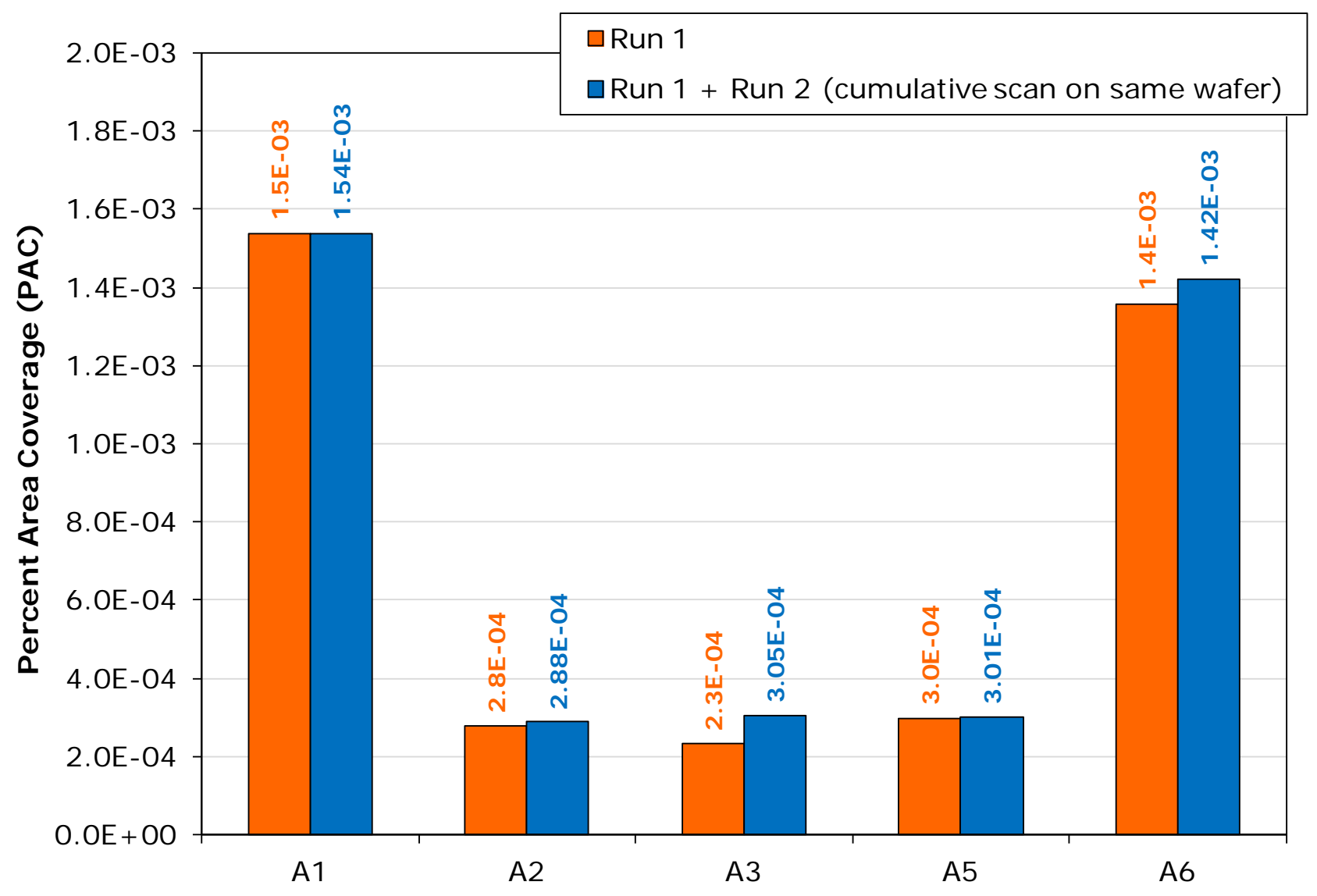

Flight Hardware Sample I D MAC-FUV-A\# 


\section{Test Results}

\section{Percent Area Coverage (PAC)}

- Based on total area covered by particles over total area scanned by IA microscope

$$
\text { PAC }=\frac{\text { Particle Obscured Area }}{\text { Wafer Scan Area }} * 100
$$

\section{RUN 2}

\section{Two Acoustic "Shakes"}

- Reflects the particle fall-out from the second simulated acoustic vibration only

- Shows at least 95 percent particulate fall-out reduction

- Outlier: A3

\begin{tabular}{|c|c|}
\hline $\begin{array}{c}\text { Flight } \\
\text { Hardware } \\
\text { Sample ID }\end{array}$ & $\begin{array}{c}\text { Particulate } \\
\text { Fall-out } \\
\text { Reduction }\end{array}$ \\
\hline A1 & $100 \%$ \\
\hline A2 & $97 \%$ \\
\hline A3 & $69 \%$ \\
\hline A5 & $99 \%$ \\
\hline A6 & $95 \%$ \\
\hline
\end{tabular}

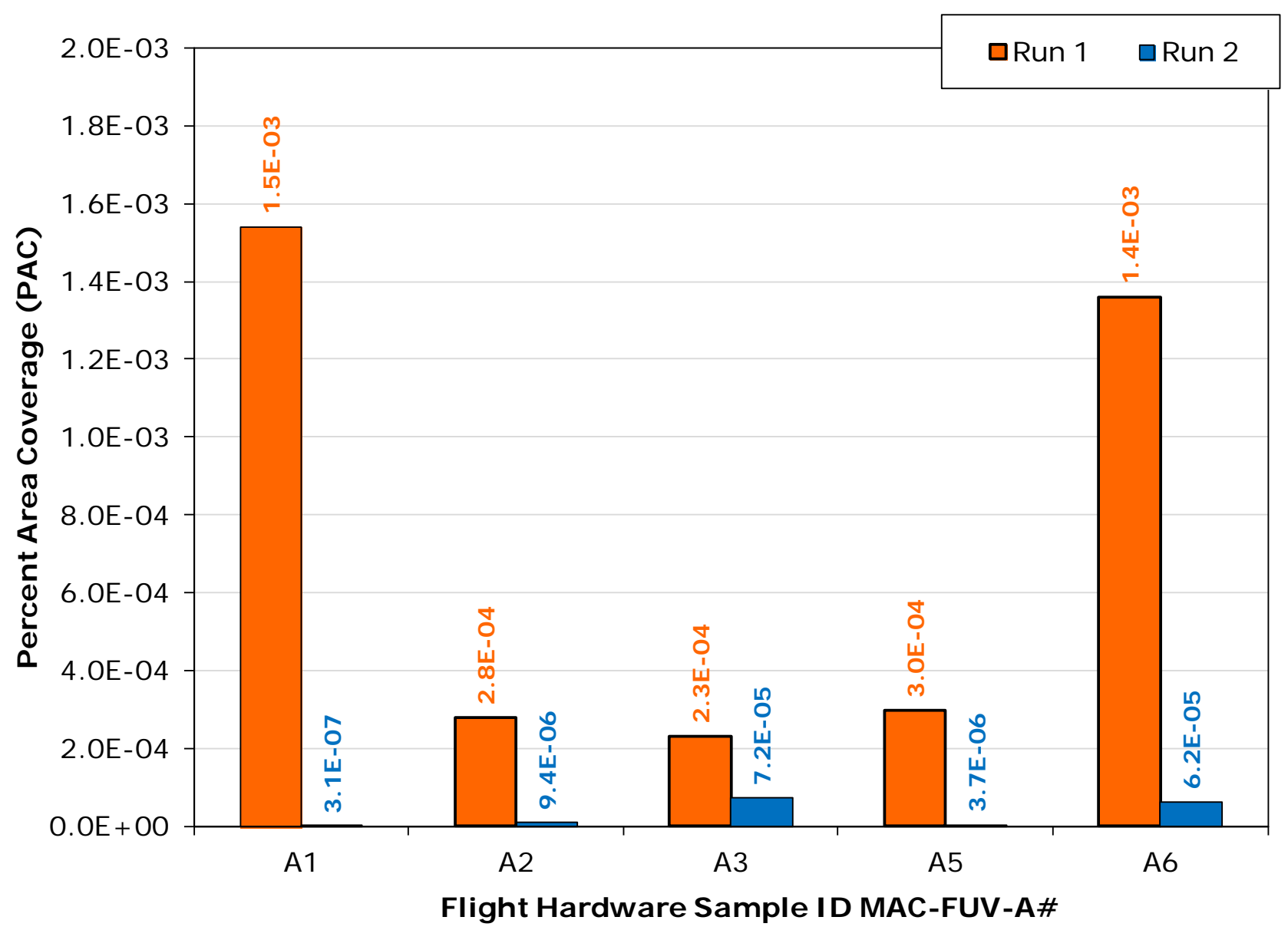




\section{Test Results}

\section{Percent Area Coverage (PAC)}

- Based on total area covered by particles over total area scanned by IA microscope

- Trend suggests that after an initial exposure to "simulated" acoustic effects, the likelihood of the coating resulting in additional particle fall-out due to vibroacoustic anomalies is very minimal

- Majority of the loose particles were removed during the first "shake" event

- These results reduce the concern for further particulate contamination
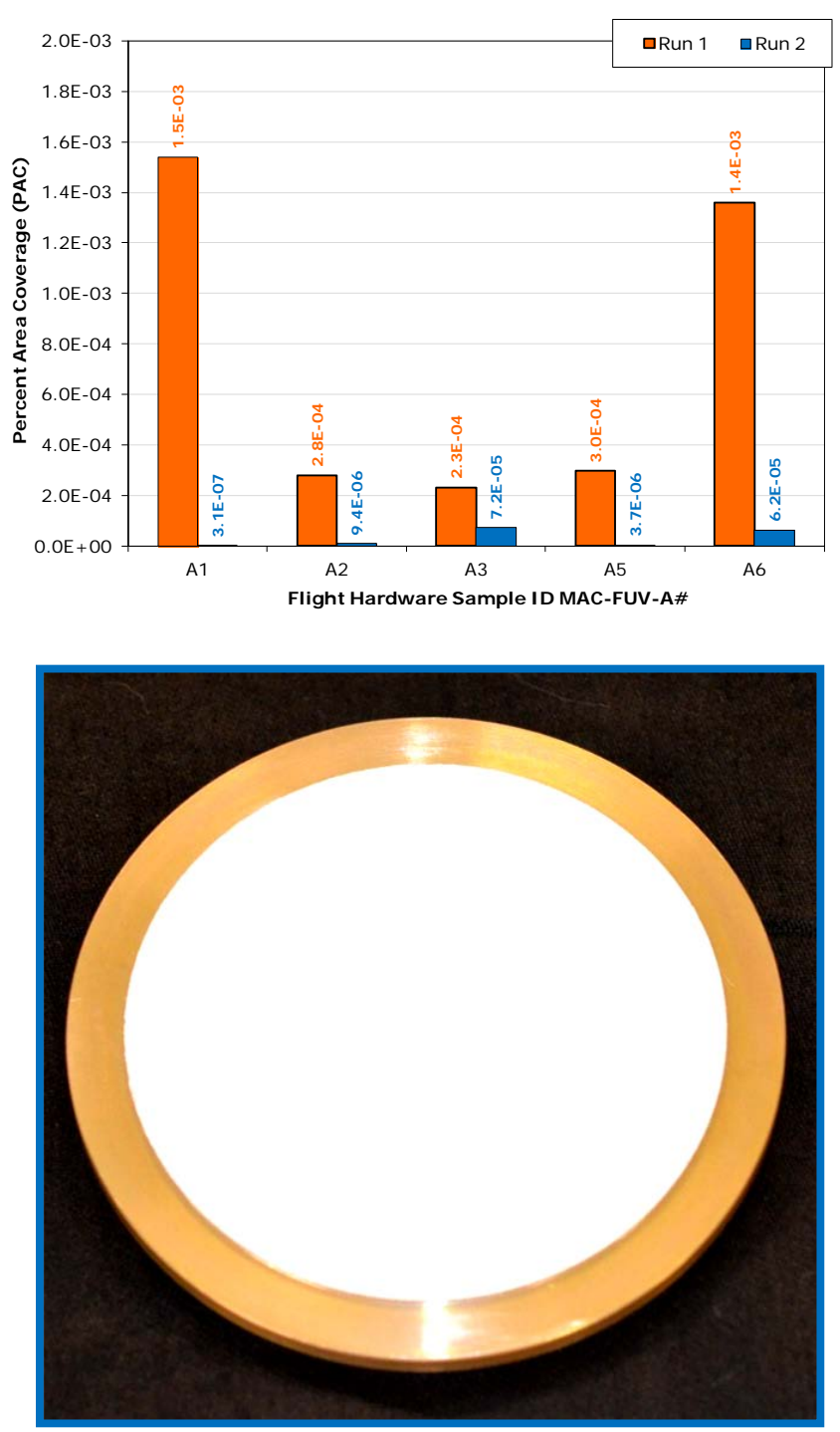

Image Credit: NASA 


\section{Test Results}

\section{Cleanliness Level (CL)}

- Based on empirical relations for surface particle obscuration from the paper "Surface particle obscuration and BRDF predictions" by Ma, Fong, \& Lee (1989)

- $\mathrm{CL}$ remained about the same after completing the second run

- This again suggests that a significant reduction of particle fall-out from the coating occurred as a result of the second acoustic induced vibrations on the hardware

\section{Assumptions}

SPHERICAL SHAPED PARTI CLES

CYLI NDRI CAL HEMI SPHERICAL SHAPED PARTI CLES

\begin{tabular}{|c|c|c|c|c|}
\hline & \multicolumn{2}{|c|}{ Cleanliness Level (sphere) } & \multicolumn{2}{c|}{ Cleanliness Level (cylinder) } \\
\hline $\begin{array}{c}\text { Flight } \\
\text { Hardware } \\
\text { Sample I }\end{array}$ & $\begin{array}{c}\text { Run 1 } \\
\text { 1 Acoustic Shake }\end{array}$ & $\begin{array}{c}\text { Run 1 + Run 2 } \\
\text { 2 Acoustic Shakes }\end{array}$ & $\begin{array}{c}\text { Run 1 } \\
\text { 1 Acoustic Shake }\end{array}$ & $\begin{array}{c}\text { Run 1 + Run 2 } \\
\text { 2 Acoustic Shakes }\end{array}$ \\
\hline A1 & 154 & 154 & 165 & 165 \\
\hline A2 & 99 & 100 & 107 & 108 \\
\hline A3 & 94 & 102 & 102 & 109 \\
\hline A5 & 101 & 101 & 109 & 109 \\
\hline A6 & 149 & 151 & 160 & 162 \\
\hline
\end{tabular}

Run 1 + Run 2 reports a cumulative scan of both runs on the same silicon wafer 


\section{Post Testing}

\section{Prepare for Shipment}

- The acoustically cleaned MAC coated flight hardware was securely packaged in shipping containers that were provided by UC Berkley

- Shipping containers were custom designed to limit contact with the MAC surface; and thereby reduce particle generation during transportation activities

- Special handing instructions for the "no touch" MAC surfaces were supplied as precaution to further reduce the risk of particulation

\section{Arrival at UC Berkeley}

- Inspection upon arrival showed almost no additional particles due to shipping and handling related activities

- Three of the six flight plates were installed inside the continuously purged FUV instrument cavity prior to instrument Thermal Vacuum (TVAC) testing

- As planned, the remaining three FUV adsorber plates were kept as flight spares

- Post vibration inspection reported no significant particulation related anomalies within the FUV cavity 


\section{Conclusions}

- Future Work

- Acknowledgements

- References

- Contact I nformation 


\section{Future Plans}

- Further investigations are expected to better understand particle fall-out characteristics of MAC

- Future plans include:

- Exploring improved (or alternative) methods of mitigating coating fall-out due to acoustic induced vibrations

- For example, on larger spaceflight hardware with particulate sensitivity requirements

- Evaluating other parameters that may introduce additional stresses within the coating structure that may contribute to particle fall-out

- For example, these parameters may include but are not limited to:

- Thermal Cycling

- Vacuum Exposure

- Shock Events

- Extended TVAC Bake-Outs

- Substrate Flexures 


\section{Acknowledgements}

- A summary of the authors of this SPIE paper, their affiliations, and support roles for this ICON/MAC effort are described below:

\section{Nithin S. Abraham}

- NASA Goddard Space Flight Center, Code 546

- MAC Research and Development Lead Coatings Engineer

- ICON Project Support Thermal Coatings Engineer

Mark M. Hasegawa

- NASA Goddard Space Flight Center, Code 546

- Thermal Coatings Application and Development Group Lead

Mark S. Secunda

- NASA Goddard Space Flight Center, Code 546

- ICON Project Support Contamination Engineer 


\section{Acknowledgements}

- The authors of this paper would like to thank the I CON Program Office at NASA GSFC and UC Berkeley for funding this coatings application and testing effort. Special thanks to:

\begin{tabular}{|c|c|c|}
\hline NAME & AFFI LI ATION & I CON Project Title \\
\hline Cathy Chou & UC Berkeley & Instrument Manager \\
\hline Mark Gummin & MIGA Motor Company & Lead Contamination Engineer \\
\hline
\end{tabular}

- The authors of this paper would also like to acknowledge some talented individuals who have contributed to this effort. Another special thanks to:

\begin{tabular}{|c|c|c|c|}
\hline NAME & AFFI LI ATI ON & NASA GSFC CODE & DESCRI PTI ON \\
\hline J ohn Petro & NASA GSFC & Code 546 & \begin{tabular}{c} 
Coatings Application Support \\
\hline Alfred Wong
\end{tabular} \\
\hline Grace Miller & SGT, Inc. & Code 546 & $\begin{array}{c}\text { Coatings Application Support } \\
\text { Image Analysis Test Support }\end{array}$ \\
\hline Kenneth O'Connor & SGT, Inc. & Code 546 & Coatings Application Support \\
\hline Kaushal Thacker & SGT, Inc. & Code 546 & Apparatus Fabrication Test Support \\
\hline Donald Gregorich & NASA Summer Intern & Code 546 & Laboratory Acoustic Test Apparatus \\
\hline Timothy Frey & NASA Summer Intern & Code 546 & Laboratory Acoustic Test Apparatus \\
\hline Evelyn Lambert & NASA Summer Intern & Code 546 & \begin{tabular}{c} 
Laboratory Acoustic Test Apparatus \\
\hline Brian Ross
\end{tabular} \\
\hline Debbie Thomas & NASA GSFC & Code 549 & $\begin{array}{c}\text { Laboratory Acoustic Test Apparatus } \\
\text { Trade Study Experiments }\end{array}$ \\
\hline
\end{tabular}




\section{References}

1. National Aeronautics and Space Administration, “Explorers Program", 1 May 2016, <http://explorers.gsfc. nasa.gov/>

2. National Aeronautics and Space Administration, "ICON Mission Overview", 1 May 2016, <http://www.nasa.gov/content/icon-missionoverview>

3. UC Berkeley Space Sciences Lab, “ICON: Ionospheric Connection Explorer”, 1 May 2016, <http://dev.icon.ssl.berkeley.edu/>

4. UC Berkeley Space Sciences Lab, “ICON: Observatory Instruments", 1 May 2016, $<$ http://dev.icon.ssl. berkeley.edu/Observatory/Instruments $>$

5. Gummin, M. “ICN_SYS_006: ICON Contamination Control Plan”, (2014)

6. Abraham, N. S., Hasegawa, M. M., and Straka, S. A., "Development and Testing of Molecular Adsorber Coatings", Proc. SPIE 8492, Optical System Contamination: Effects, Measurements, and Control 2012, 849203 (October 2012)

7. Abraham, N. S., Hasegawa, M. M., and Straka, S. A., "Black Molecular Adsorber Coatings for Spaceflight Applications", Proc. SPIE 9196, Systems Contamination: Prediction, Measurement, and Control 2014, 91960F (September 2014)

8. Abraham, N.S. "NASA Applications of Molecular Adsorber Coatings", Contamination, Coatings, Materials Science, and Planetary Protection Workshop (July 2015)

9. Abraham, N.S. "NASA Applications of Molecular Adsorber Coatings", Thermal and Fluids Analysis Workshop (August 2015)

10. Abraham, N.S., "ICON MAC Simulated Acoustic Cleaning Trade Study", Thermal Coatings Report TCR \#669 (September 2014 )

11. National Aeronautics and Space Administration, "Outgassing Data for Selecting Spacecraft Materials System", 1 May 2016, <https://outgassing. nasa.gov/>

12. National Aeronautics and Space Administration, "Payload Vibroacoustic Test Criteria", NASA-STD-7001A Technical Standard (J anuary 2011)

13. National Aeronautics and Space Administration, "Spacecraft Dynamic Environments Testing", NASA-HDBK-7008 Technical Standard (July 2014)

14. National Aeronautics and Space Administration, "Facilities and Resources at Goddard", 1 May 2016, <http://www. nasa.gov/centers/goddard/about/unique_resources.html>

15. ACS Acoustic Cleaning Systems, "Acoustic Cleaning", 1 May 2016, <http://www.acousticcleaning.com/cleaning.html>

16. Primasonics, "Acoustic Cleaners", 1 May 2016, <http://www.primasonics.com/acoustic-cleaning/acoustic-cleaners>

17. Kosko, B., Noise, New York: Viking, (2006)

18. Ma, P. T., Fong, M. C., and Lee, A. L., "Surface Particle Obscuration and BRDF Predictions", Proc. SPIE Vol. 1165, Scatter from Optical Components (1989) 


\section{Contact I nformation}

\section{Nithin S. Abraham}

\section{Thermal Coatings Engineer}

NASA Goddard Space Flight Center, Code 546

Contamination and Coatings Engineering Branch

E-mail: nithin.s.abraham@nasa.gov

Phone: (301) 614-7070 